\title{
BMJ Global Health Evidence-based interventions to reduce mortality among preterm and low- birthweight neonates in low-income and middle-income countries: a systematic review and meta-analysis
}

To cite: Kleinhout MY, Stevens MM, Osman KA, et al. Evidence-based interventions to reduce mortality among preterm and low-birthweight neonates in low-income and middle-income countries: a systematic review and meta-analysis

BMJ Global Health

2021;6:e003618. doi:10.1136/ bmjgh-2020-003618

Handling editor Seye Abimbola

MYK and MMS contributed equally.

Received 3 August 2020 Revised 23 December 2020 Accepted 25 December 2020

Check for updates

C Author(s) (or their employer(s)) 2021. Re-use permitted under CC BY-NC. No commercial re-use. See rights and permissions. Published by BMJ.

For numbered affiliations see end of article.

Correspondence to

Merel M Stevens;

merel.stevens@hotmail.com

\section{ABSTRACT}

Background Preterm birth is the leading cause of under-fivemortality worldwide, with the highest burden in low-income and middle-income countries (LMICS). The aim of this study was to synthesise evidence-based interventions for preterm and low birthweight (LBW) neonates in LMICs, their associated neonatal mortality rate (NMR), and barriers and facilitators to their implementation. This study updates all existing evidence on this topic and reviews evidence on interventions that have not been previously considered in current WHO recommendations.

Methods Six electronic databases were searched until 3 March 2020 for randomised controlled trials reporting NMR of preterm and/or LBW newborns following any intervention in LMICs. Risk ratios for mortality outcomes were pooled where appropriate using a random effects model (PROSPERO registration number: CRD42019139267).

Results 1236 studies were identified, of which 49 were narratively synthesised and 9 contributed to the metaanalysis. The studies included 39 interventions in 21 countries with 46993 participants. High-quality evidence suggested significant reduction of NMR following antenatal corticosteroids (Pakistan risk ratio (RR) $0.89 ; 95 \% \mathrm{Cl} 0.80$ to 0.99 |Guatemala $0.74 ; 0.68$ to 0.81$)$, single cord $(0.65 ; 0.50$ to 0.86$)$ and skin cleansing with chlorhexidine (0.72; 0.55 to 0.95$)$, early BCG vaccine $\left(0.64 ; 0.48\right.$ to $\left.0.86 ; I^{2} 0 \%\right)$, community kangaroo mother care (OR $0.73 ; 0.55$ to $0.97 ;\left.\right|^{2} 0 \%$ ) and home-based newborn care (preterm $0.25 ; 0.14$ to 0.48 ILBW $0.42 ; 0.27$ to 0.65 ). No effects on perinatal (essential newborn care 1.02; 0.91 to 1.14 Ineonatal resuscitation 0.95 ; 0.84 to 1.07 ) or 7 day NMR (essential newborn care 1.03; 0.83 to 1.27Ineonata resuscitation $0.92 ; 0.77$ to 1.09 ) were observed after training birth attendants.

Conclusion The findings of this study encourage the implementation of additional, evidence-based interventions in the current (WHO) guidelines and to be selective in usage of antenatal corticosteroids, to reduce mortality among preterm and LBW neonates in LMICs. Given the global commitment to end all preventable neonatal deaths by 2030 , continuous

\section{Key questions}

What is already known?

- Preterm birth and low birth weight in low-income and middle-income countries (LMICs) are responsible for one of the highest preventable neonatal deaths and disability-adjusted life years (DALYs) globally.

- In 2015, the WHO published recommendations on interventions to improve preterm birth outcomes, focusing on nine antenatal, perinatal and postnatal interventions, and their maternal and neonatal outcomes.

- To date, the vast majority of published research on interventions for preterm and low-birthweight (LBW) neonates has been conducted in high-income countries.

What are the new findings?

- To our knowledge, this is the first systematic review and meta-analysis that updates all existing evidence and provides an overview of new evidence regarding mortality outcomes for preterm and LBW neonates in LMICs.

- Four effective interventions currently not included in the WHO guidelines were identified: cord and skin cleansing with chlorhexidine, community kangaroo mother care for all LBW neonates $<2500 \mathrm{~g}$, home-based newborn care and early BCG vaccination for LBW neonates.

- Antenatal corticosteroids are effective under certain circumstances.

- A reporting gap for neonatal mortality outcomes for studies with a focus on antenatal and population-based interventions for preterm and LBW neonates was identified.

evaluation and improvement of the current guidelines should be a priority on the agenda.

\section{BACKGROUND}

Globally, an estimated 15 million infants are born prematurely each year. ${ }^{1}$ Complications in 


\section{Key questions}

What do the new findings imply?

- The novel findings of this study encourage the implementation of additional, evidence-based methods to reduce the neonatal mortality rate among preterm and LBW neonates.

- Optimal use of maternal and newborn healthcare practices, such as accurate gestational age dating, birth and death registration, and a health system in which continuous knowledge generation is embedded in daily practice, remain priorities to inform future practice.

- The findings highlight the importance of disaggregated data presentation to increase the availability of neonatal mortality outcomes for preterm and LBW neonates in LMICs.

preterm birth are the leading cause of death in children under 5 years of age globally and accounted for approximately $35 \%$ of 2.5 million deaths among all newborn babies in $2018 .^{2}$ An estimated $81.1 \%$ of preterm births occurred in Asia and sub-Saharan Africa and $>80 \%$ of all newborn deaths among preterm and low-birthweight (LBW) neonates occurred in these countries. ${ }^{13}$ Low-income and middle-income countries (LMICs) are disproportionately affected due to their lack of available, affordable, acceptable and sufficient-quality maternal and newborn care. Moreover, LMICs continue to deal with shortages of trained health personnel and healthcare technology such as incubators and respiratory support systems. This may cause an increased incidence of disability among preterm and LBW babies, who survive the neonatal period. ${ }^{4}$

Addressing the global burden of preterm birth and LBW babies is crucial to achieve Sustainable Development Goal (SDG) 3.2 and end the preventable deaths of newborns and children under 5 years of age. About $84 \%$ of preterm births are moderate and late preterm (32-<37 weeks), whose deaths could be prevented with supportive care and feasible interventions. ${ }^{5}$ In 2014, the WHO and UNICEF launched the Every Newborn Action Plan (ENAP), a global roadmap with strategic actions to end preventable newborn mortality and stillbirth by $2035 .{ }^{3}$ In 2015 , the WHO published recommendations on interventions to improve preterm birth outcomes. ${ }^{4}$ This recommendation focused on improving maternal and neonatal outcomes associated with preterm birth. Evidence for nine interventions, identified through a scoping exercise among international stakeholders, was synthesised into a guideline.

Gestational age determination in LMIC settings is known to be challenging. Because of this, a proportion of labelled preterm babies are in fact growth-restricted term neonates. LBW babies are at increased risk of early mortality. They need different strategies and approaches than preterm babies. Neonates that are both preterm and growth retarded are at even higher risk of complications and adverse outcomes. ${ }^{67}$ In the current WHO guidelines, fetal growth restriction is not addressed. Interventions aimed at optimising outcomes for LBW neonates were therefore included in this study.

This manuscript updates all existing evidence on reduction of neonatal mortality among preterm and/or
LBW neonates in LMICs and reviews evidence on interventions that have not been previously considered in the current WHO recommendations.

\section{METHODS}

\section{Search strategy and selection criteria}

This systematic review and meta-analysis was registered with the PROSPERO registry for systematic reviews (CRD42019139267), conducted according to the Cochrane methodology, ${ }^{8}$ and reporting adhered to Preferred Reporting Items for Systematic Reviews and Meta-Analyses (PRISMA) guidelines. ${ }^{9}$ Ethics approval was not required for this literature research. No human or animal participants were involved.

Randomised controlled trials (RCTs) of interventions for preterm and LBW neonates in LMICs with reported neonatal mortality outcomes were eligible for inclusion. These included studies on maternal and neonatal interventions preconception, antepartum, intrapartum or postpartum up to 28 days of life. Given the circumstances and challenges accompanied with conducting an RCT in a low-resource setting and the high number of prepost intervention studies (before-after design) in our search results, we decided to also include this research design in our review. Exclusion criteria were conference abstracts, reports, editorials, presentations, project protocols, full text unavailable in English or Spanish. We did not include reviews from high-income settings. The rationale behind this is the fact that interventions effective in high-income settings cannot be translated to low-resource settings untested, and circumstances are too different to compare results. Preterm and LBW neonates were defined as $<37.0$ weeks of gestation and birth weight $<2500 \mathrm{~g}$, respectively. ${ }^{3}$ Mortality definitions were according to WHO (online supplemental appendix 2).$^{10}$ LMICs were defined according to the World Bank classification. ${ }^{11}$ Meta-analysis was performed for studies reporting on the same intervention with similar mortality outcomes.

The search was conducted by MS and MK in six electronic databases from database inception to 3 March 2020: Pubmed/MEDLINE, The Cochrane Library, EMBASE, POPLINE, The Global Health Library and African Journals Online. For every database, a search string was developed with the support of a librarian. Predefined search (title/abstract), MeSH terms, text words and word variants were used to identify preterm and LBW neonates combined with perinatal, neonatal, or infant mortality or survival. The Cochrane Highly Sensitive Search Strategies were used to identify randomised trials in $\mathrm{MEDLINE}^{8}$ and BMI Search Blocks ${ }^{12}$ to identify LMICs. References were manually searched for additional studies (snowballing). Limits were only applied for the Global Health Library (English). The full search strings are available in .

Endnote reference software (V.X9) was used to remove duplicates both automatically and manually. Subsequently, MS and MK independently screened articles 
based on title and abstract using the web application Rayyan. ${ }^{13}$ Studies screened in full text were exported as pdfs to Endnote. Full-text screening was performed by MS and checked by MK. In disagreements, JLB was consulted and articles discussed until consensus was reached. Authors were contacted once when full texts were inaccessible.

\section{Data analysis}

MS and MK conducted data extraction supported by JLB. A standardised, piloted data extraction sheet was created with the following information: study design, country and setting, sample size, mean gestational age, mean birth weight, neonatal mortality outcome and secondary outcomes. Outcome measurements were noted as percentages and relative risk ratios (RR). The corresponding author was emailed once when there were incomplete data. A statistician was consulted in the case of statistical or methodological uncertainties.

Bias was assessed using the Revised Cochrane Riskof-Bias tool for randomised trials (RoB 2) and the Risk Of Bias In Non-randomised Studies of Interventions (ROBINS-I) tool for before-after studies. ${ }^{14}{ }^{15}$ As mortality estimates are suggested to be unaffected by lack of blinding, ${ }^{16}$ risk of bias of open-label studies was not
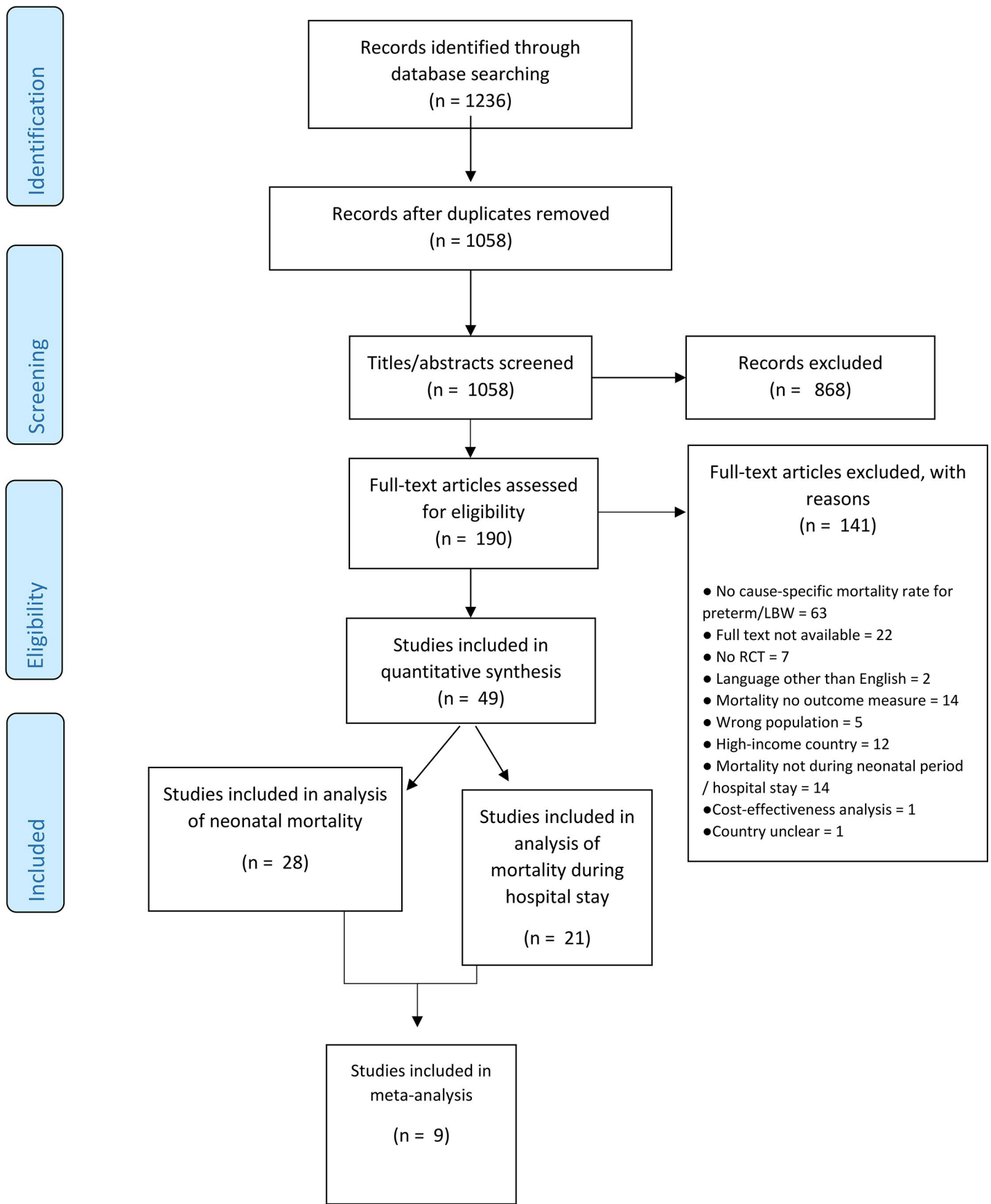

Figure 1 PRISMA (Preferred Reporting Items for Systematic Reviews and Meta-Analyses) flowchart study selection. RCT, randomised controlled trial. 
increased solely due to unblinded participants, carers or outcome assessors. Cluster RCTs were also assessed on bias arising from the recruitment of individual participants after randomisation with clearly defined inclusion criteria established prior to randomisation considered as low risk of bias. Bias assessment was conducted by MS, with random samples double-checked for accuracy (MK), supported by JLB and/or an external statistician. The evidence quality was assessed across studies according to the Grading of Recommendations Assessment, Development, and Evaluation (GRADE) system. ${ }^{17}$ An explanation of the GRADE certainty ratings can be found in online supplemental appendix 7 .

Quantitative results of (neonatal) mortality rates (NMRs) were summarised in an evidence table with counts, frequencies including, RR with $95 \%$ CI and $\mathrm{p}$ value, according to intervention. RRs of cluster RCTs retrieved from the study results and RRs of individually randomised studies were computed using RevMan V.5.3. ${ }^{18}$ For comparable interventions and outcomes, the RRs were pooled in a meta-analysis using the randomeffects model with RevMan V.5.3. ${ }^{18}$ A post hoc analysis of studies on in-hospital mortality was performed because of the uncertainty in outcome definition, but there was a high likelihood that these studies predominantly incorporated the neonatal period in their mortality outcome measure. Likewise, RRs with 95\% CI and p value of in-hospital mortality were computed using RevMan V.5.3. ${ }^{18}$ RRs of in-hospital mortality reported in the stepped-wedge cluster RCT were retrieved from the study results.

In addition to the Cochrane methodology for conducting a systematic review, a strengths, weaknesses, opportunities and threats (SWOT) analysis was done by MS with support from MK and JLB. The rationale behind conducting a SWOT analysis was the analytical framework it provides for the identification of internal (strengths and weaknesses) and external factors (opportunities and threats) that influence the effect of interventions and thereby translate research into practice. ${ }^{19}$ The SWOT analysis for each intervention was predominantly based on the included articles.

\section{Patient and public involvement}

Due to the nature of this literature study, patients or the public were not involved in the design, conduct, reporting or dissemination plans of our research.

\section{RESULTS}

In total, 1058 articles were identified through database searching after removing duplicates (figure 1). After title and abstract screening, 190 articles were screened in full text, of which 49 were included reporting on 39 different interventions. Of these, 41 were (cluster) randomised trials, 7 were before-after studies, and 1 was both combined. Twenty-eight studies were included in the primary analysis on neonatal mortality ${ }^{20-47}$; in-hospital mortality was reported from the other 21 . This subgroup of studies was included in a post hoc analysis. ${ }^{48-68}$ Nine studies reported on five similar interventions: early BCG vaccine, community kangaroo mother care (KMC), topical ointment with sunflower seed oil, topical ointment with Aquaphor and bubble CPAP. The results were pooled into a meta-analysis. ${ }^{23} 2431343540456066$

Tables 1 and 2 present an overview of study characteristics. The included studies were published in 1989-2020 and included 46993 participants. Studies were conducted in 21 different countries, of which 8 were in low-income countries, 30 were in lower middle-income countries and 7 were in upper middle-income countries (online supplemental appendix 7). Two studies were conducted in multiple LMICs, including a main publication and two subanalyses of the same study. ${ }^{2022} 3639$

Thirty-nine interventions were identified in 49 articles. The interventions were related to the antenatal period $(\mathrm{n}=2),{ }^{20} 21363943$ infection and sepsis prevention $(\mathrm{n}=11), 23242627313435373846486264$ feeding $(\mathrm{n}=3), 254267$ newborn care strategies $(\mathrm{n}=5),{ }^{22} 28-30404145474953$ prevention and treatment of respiratory morbidity $(\mathrm{n}=$ 12), ${ }^{515254-61636566}$ and others $(\mathrm{n}=5) .{ }^{32} 33445068$

Different definitions of mortality were studied. Two studies reported on the rate of stillbirths, ${ }^{2022}$ three studies included perinatal mortality ${ }^{20-22}$ two studies reported on 7-day neonatal mortality ${ }^{20}{ }^{22}$ and one study reported on 21-day neonatal mortality. ${ }^{23}$ Twenty-five studies included mortality at 28 days of postnatal age. ${ }^{20-47}$ Twenty studies reported in-hospital mortality and death at 36 weeks and one study recorded the gestational age from the last menstrual period. ${ }^{48-68}$

Table 3 presents an overview of the quantitative results including studies' quality of evidence assessing neonatal mortality, table 4 presents in-hospital mortality, and figure 2 presents meta-analyses (online supplemental appendix 10). Figures 3 and 4 show a visual overview of interventions, study characteristics and quality of evidence. Interventions showing results with high or moderate certainty evidence are narratively discussed in detail. Studies yielding (very) low-quality results are not discussed in detail. figures 3 and 4

Neonatal mortality and in-hospital mortality results are described separately. Studies of high, moderate and low quality are highlighted under different subheadings.

\section{Neonatal mortality}

High quality

Thirteen studies were considered of high quality. They evaluated antenatal corticosteroids treatment, skin cleansing with chlorhexidine, early BCG, community KMC, home-based newborn care and training birth attendants. ${ }^{20} 222427-313639404546$

Antenatal corticosteroids (ACS) treatment for pregnant women at $24^{0 / 7}-35^{6 / 7}$ weeks of gestation versus standard care was studied in six MICs. ${ }^{20}$ No significant differences were found in stillbirth, perinatal mortality or 7-day NMR rates. The 28-day NMR varied among the six different study sites. Two subanalyses reported 28-day NMR for 


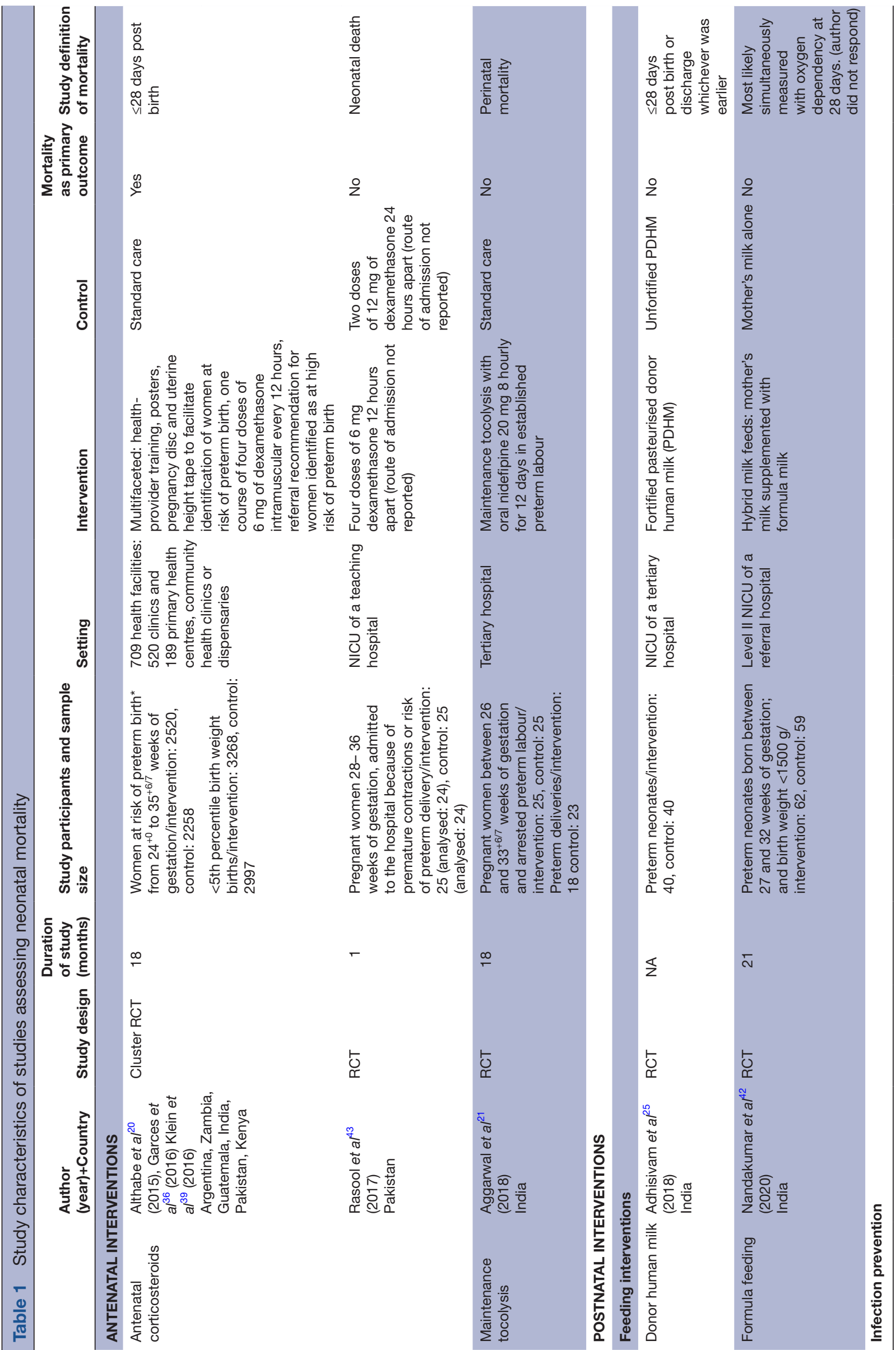




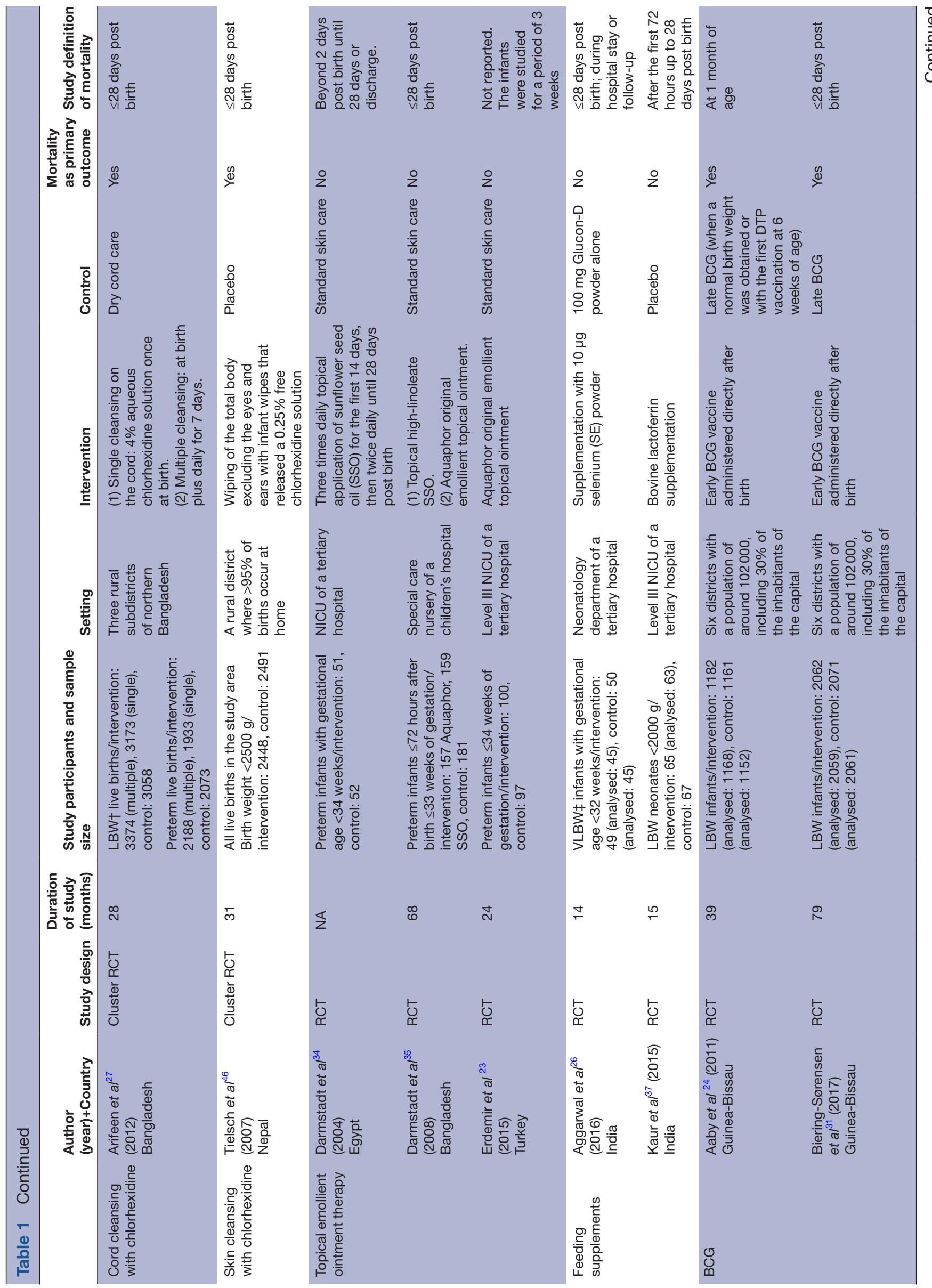




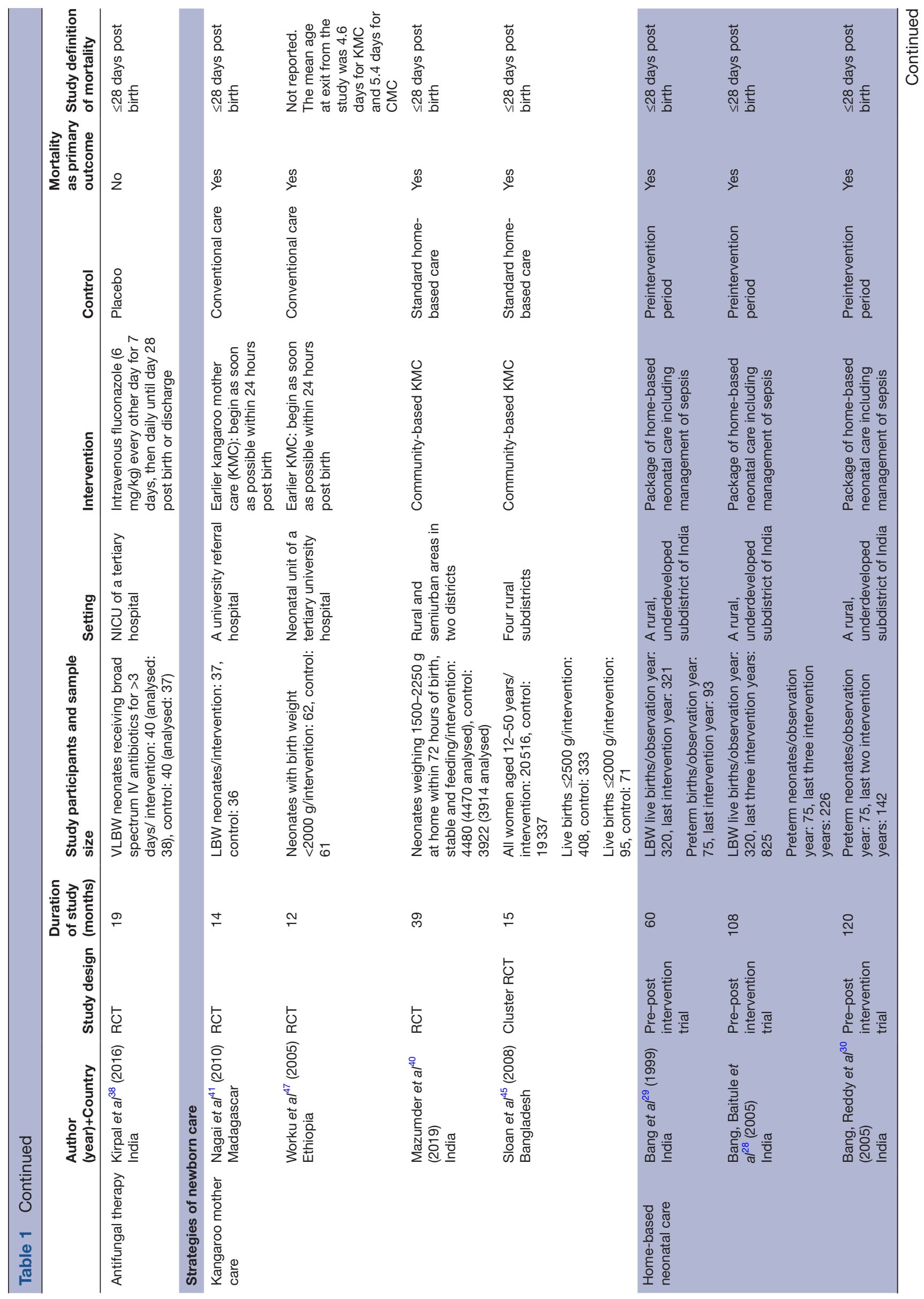




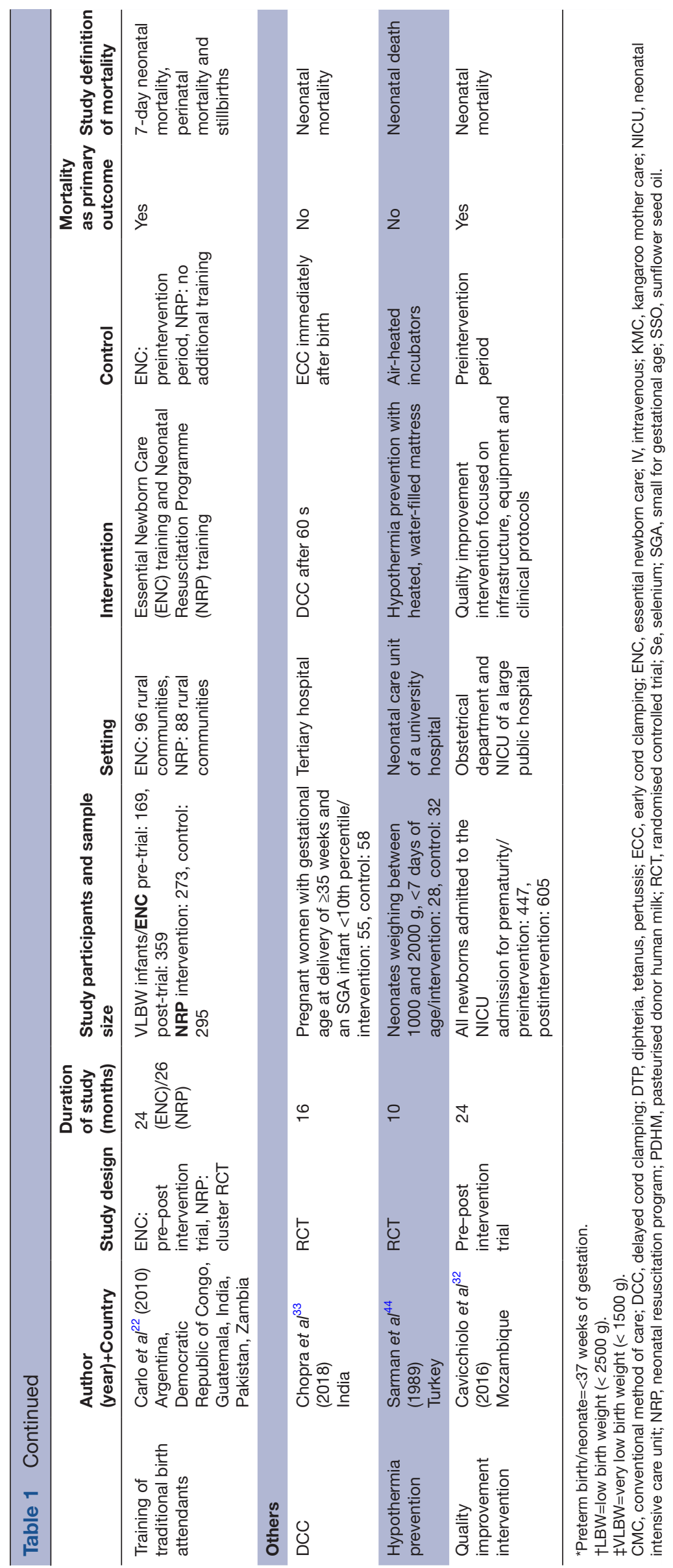

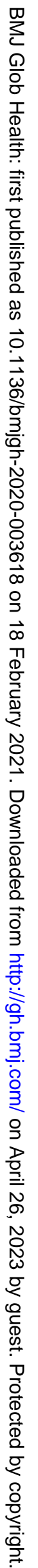




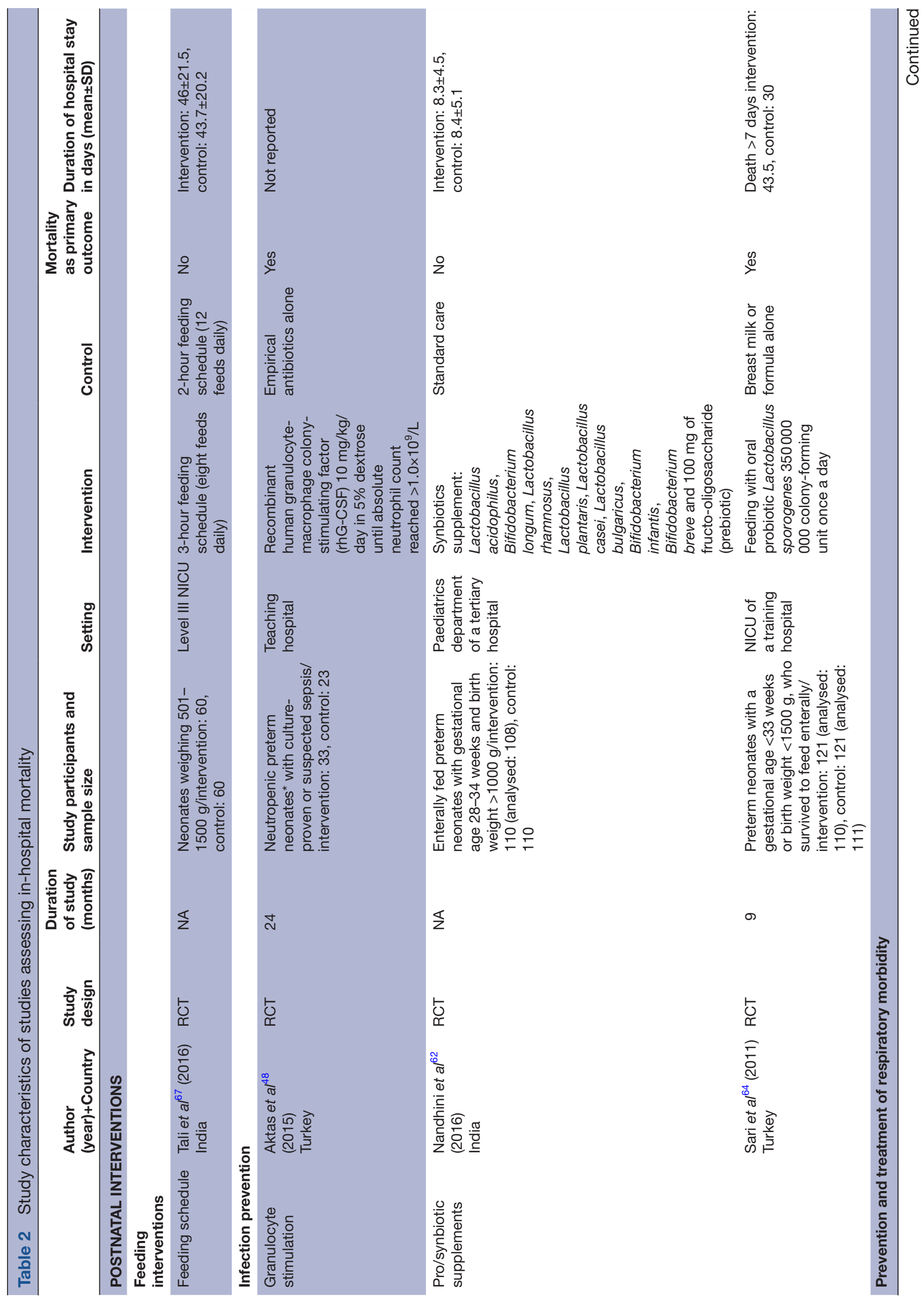




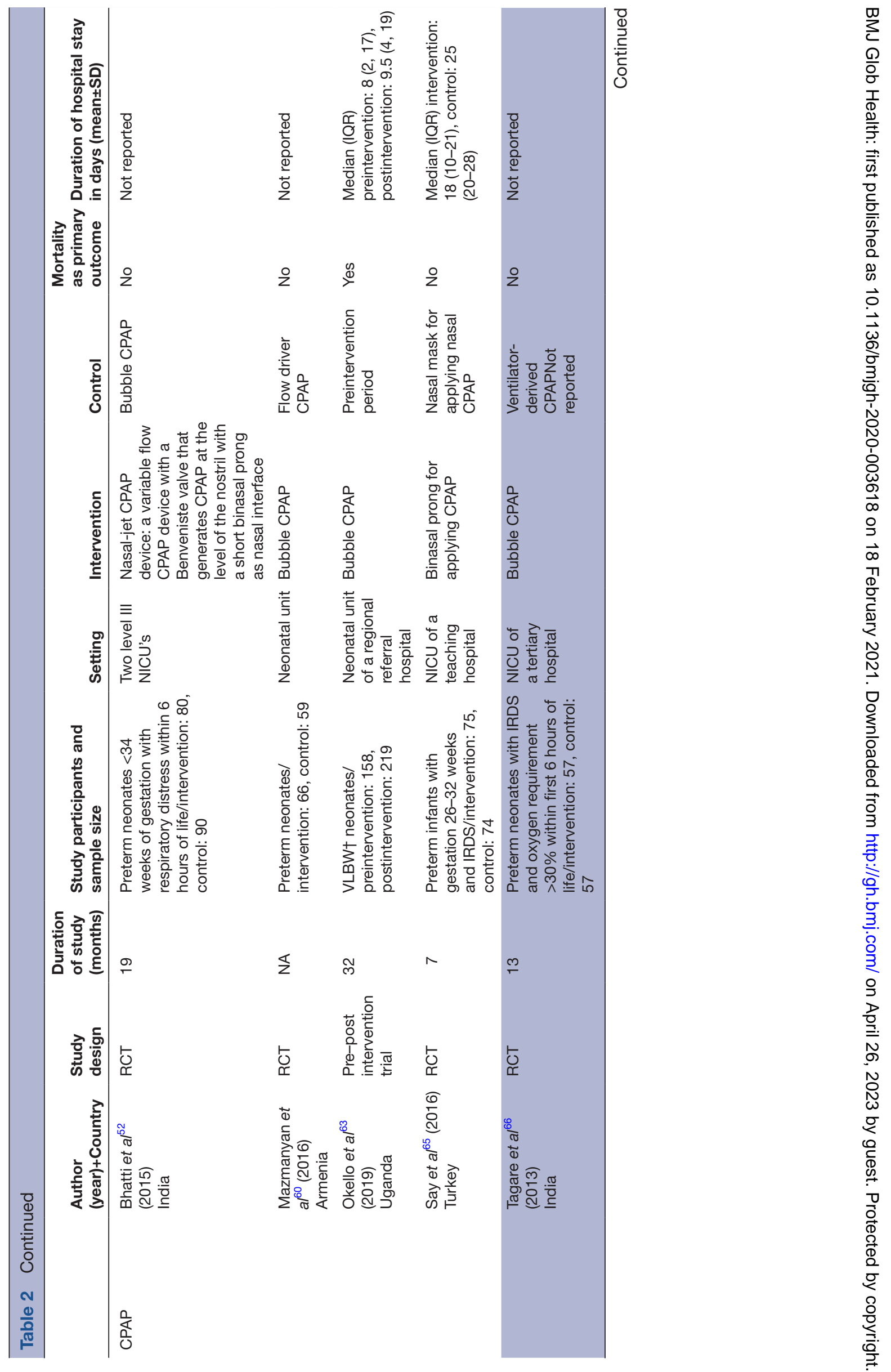




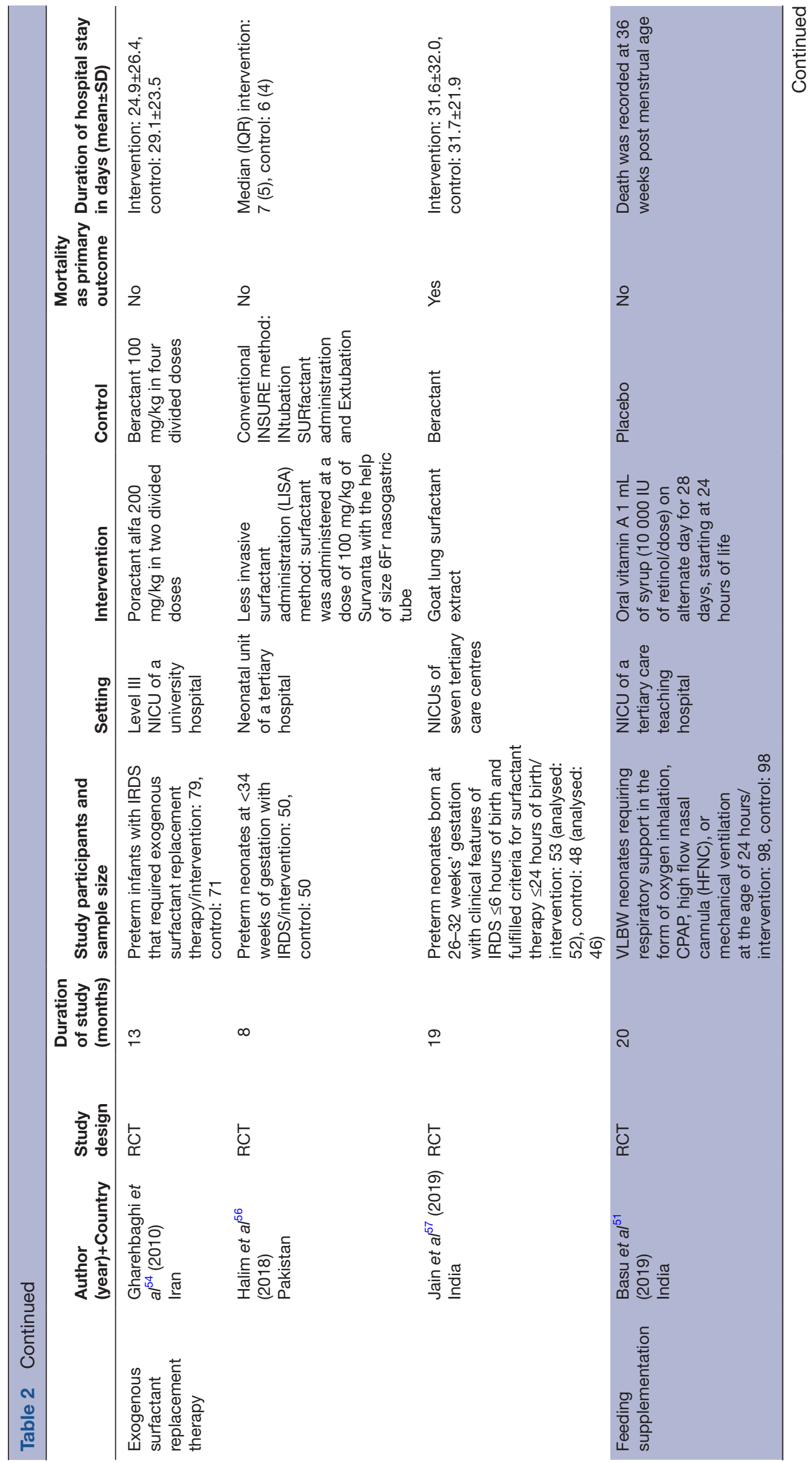




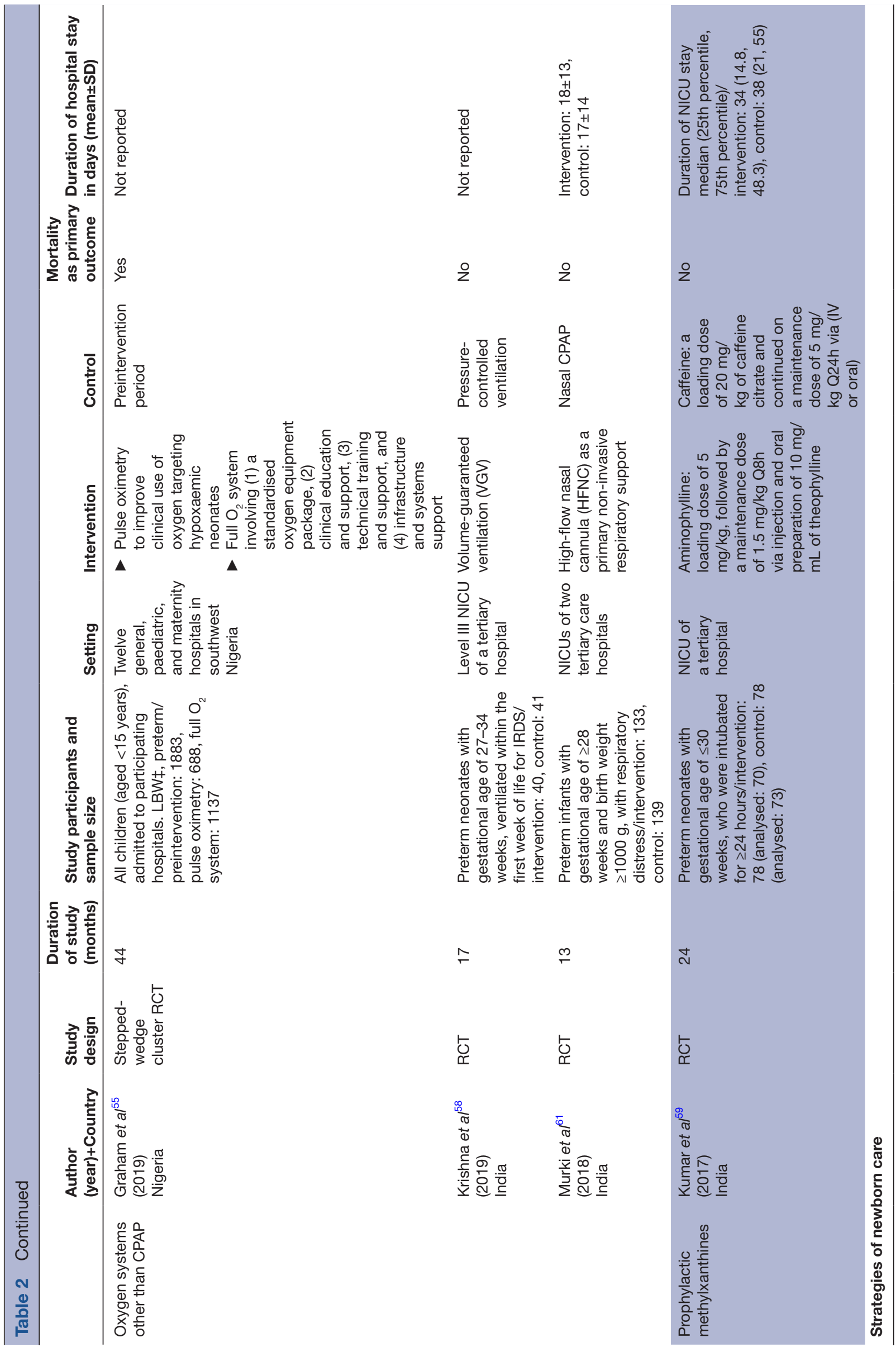




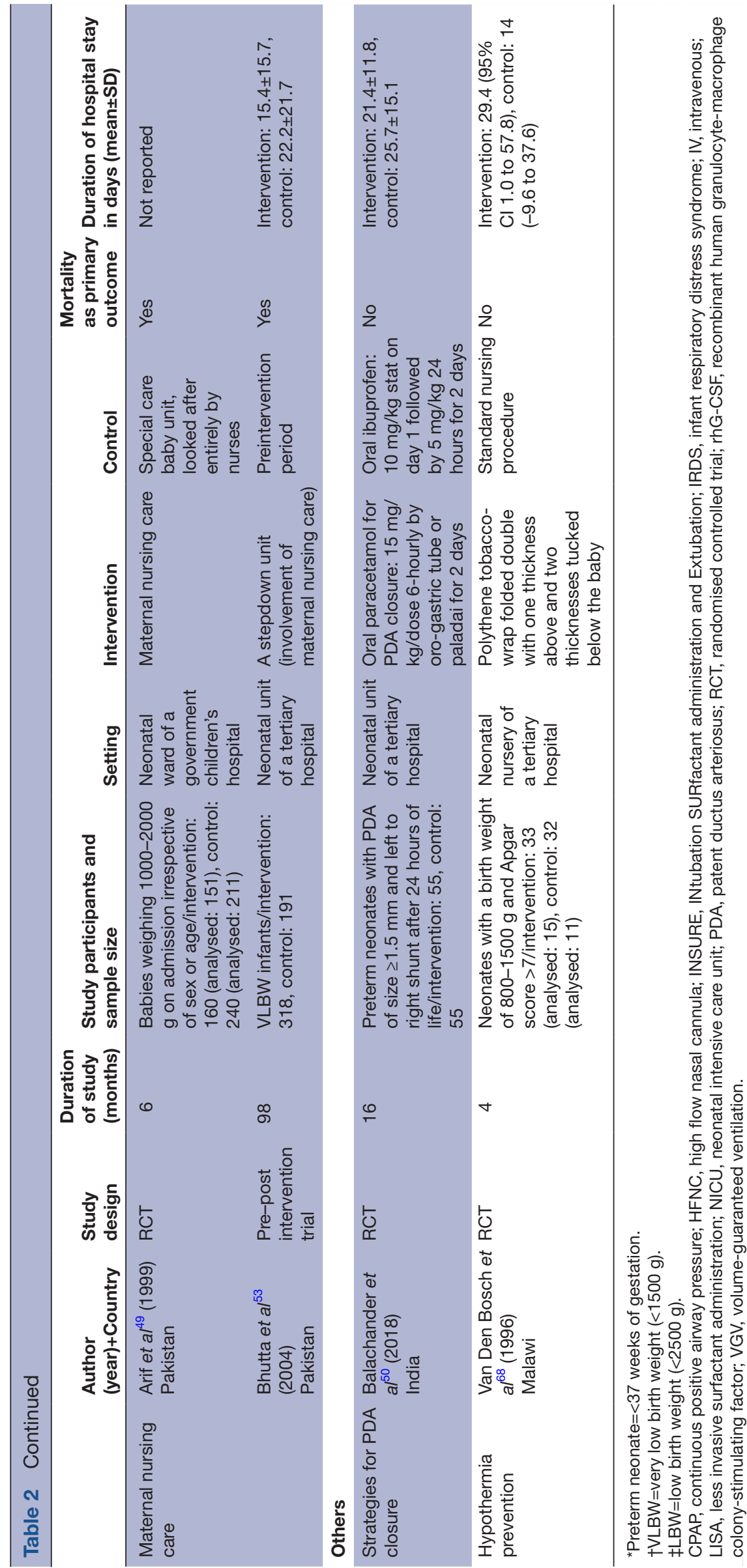




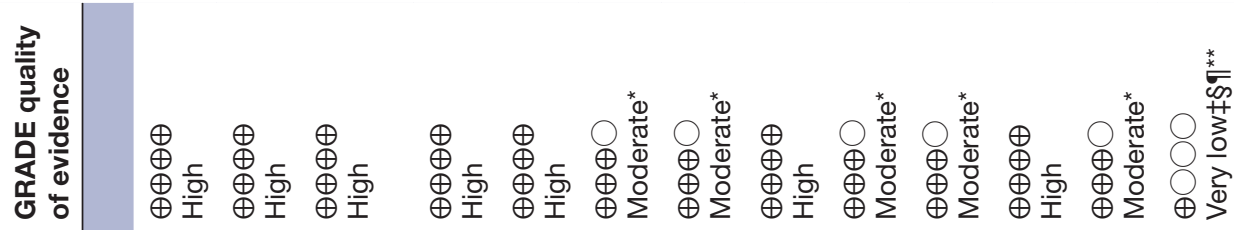

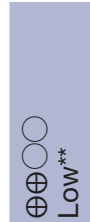

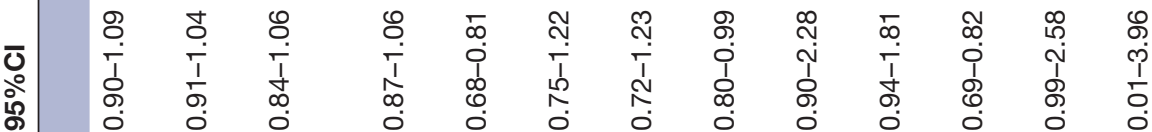

$\overrightarrow{0}$

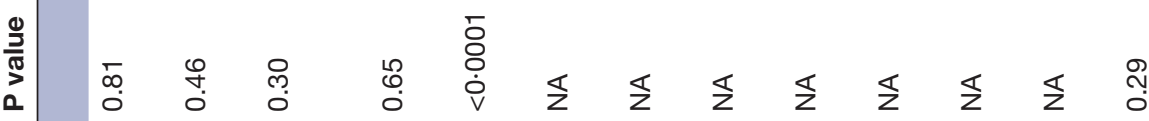

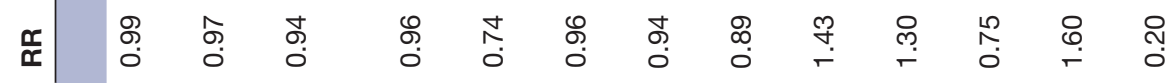

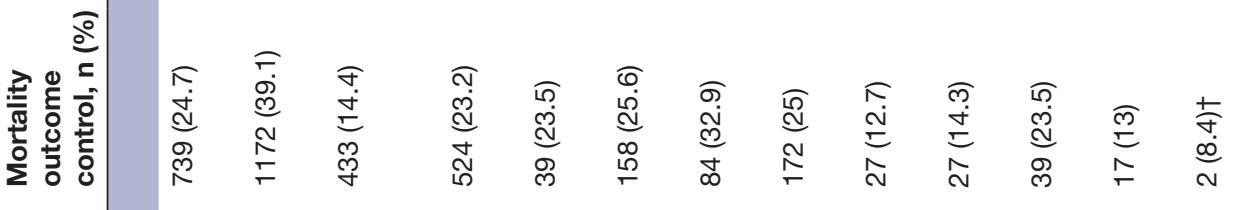

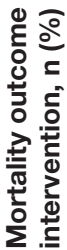

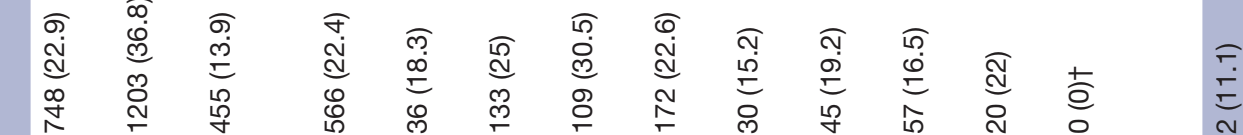

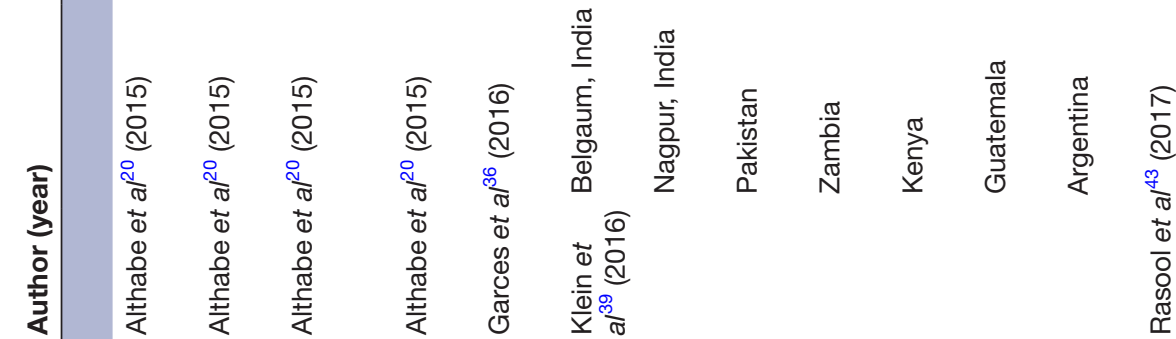
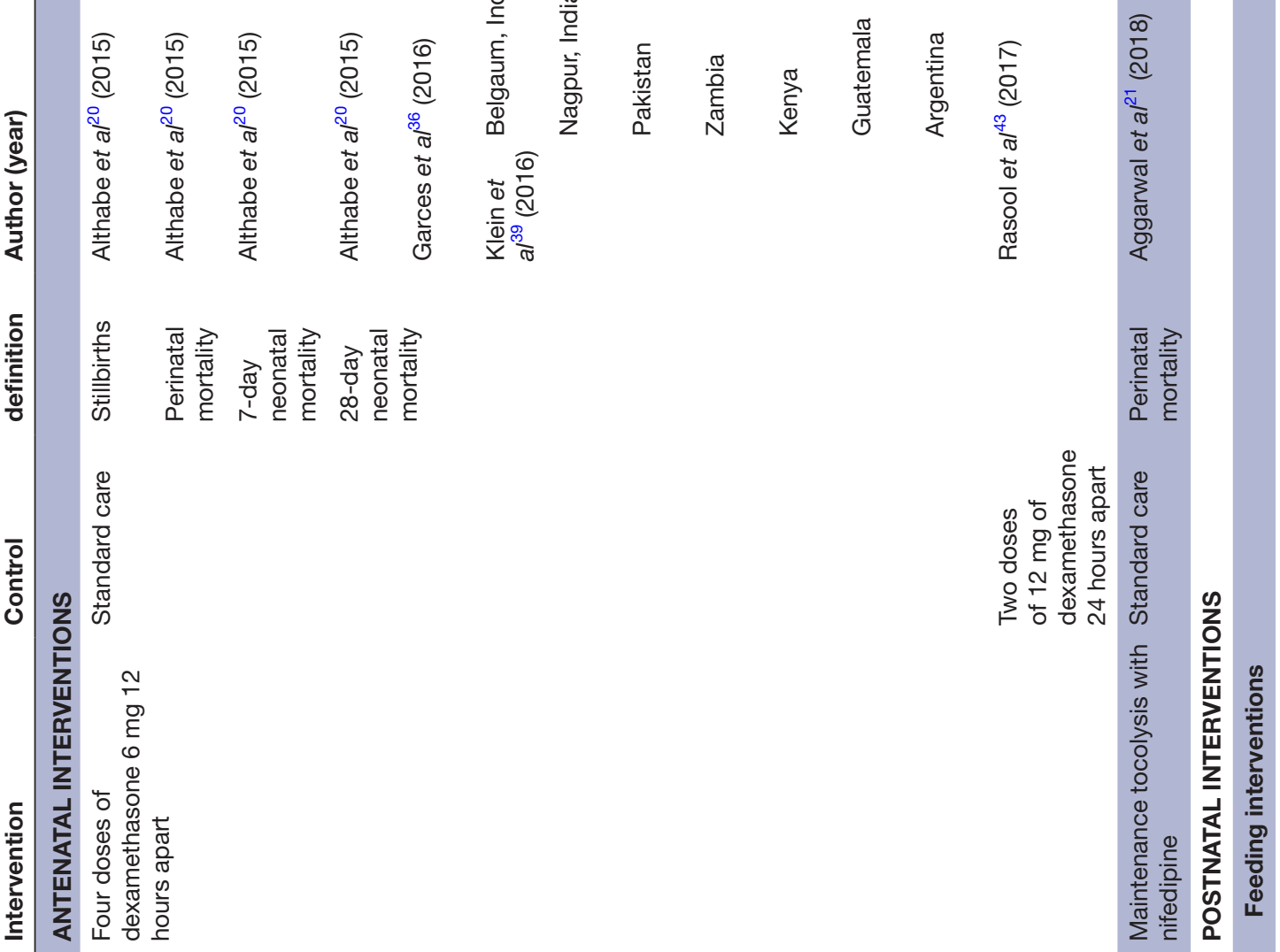

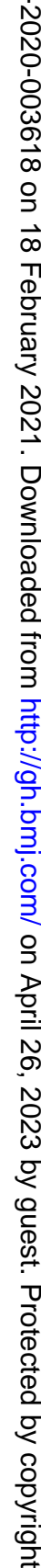




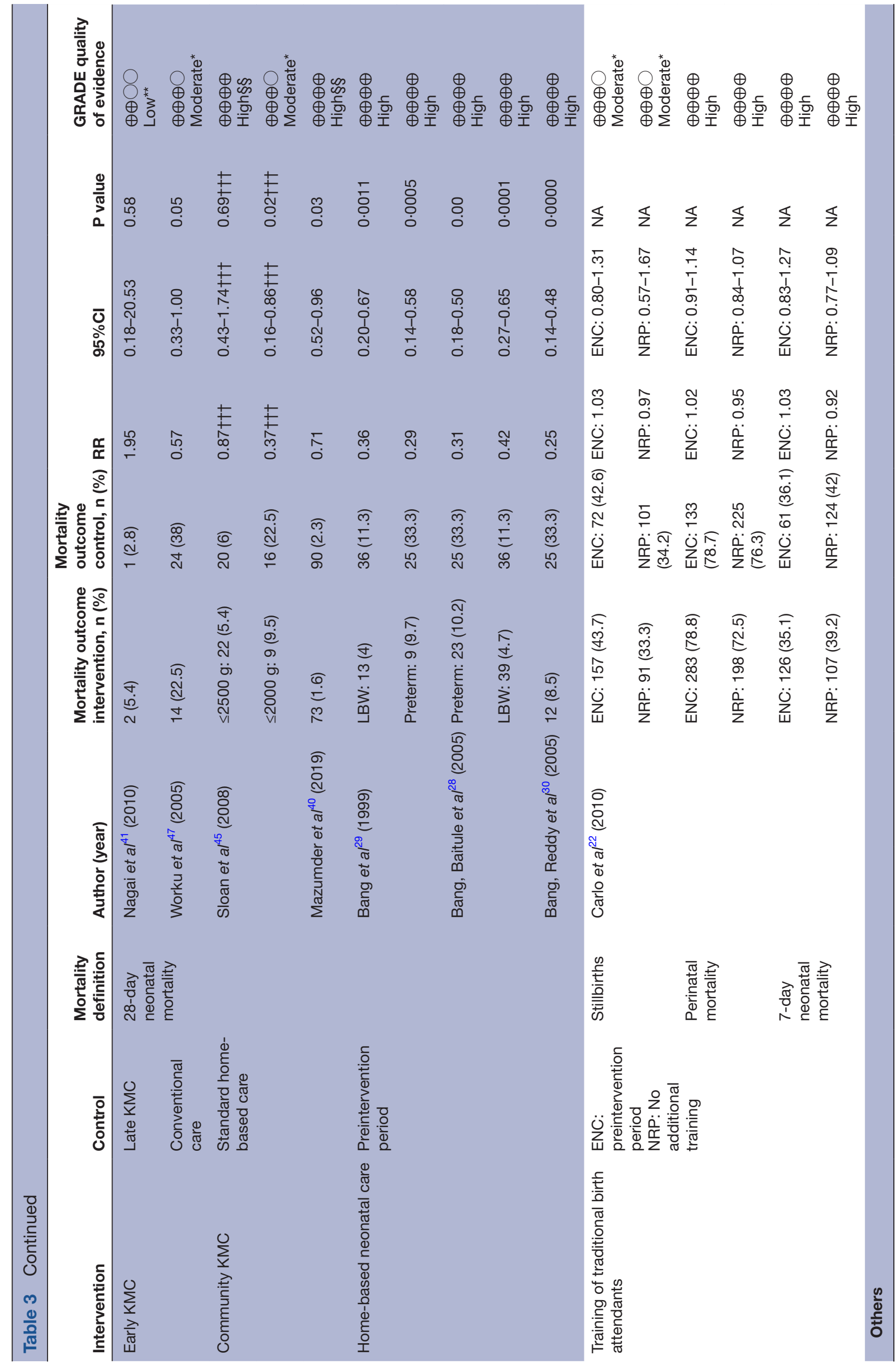




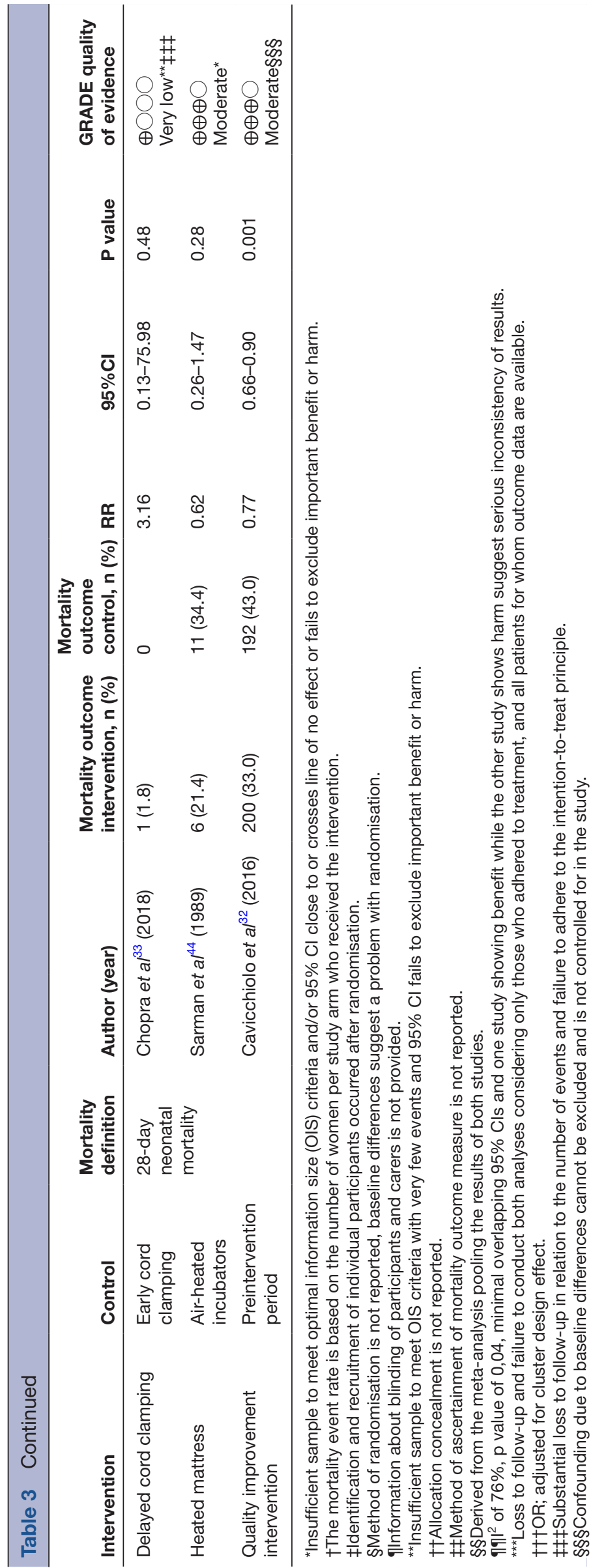

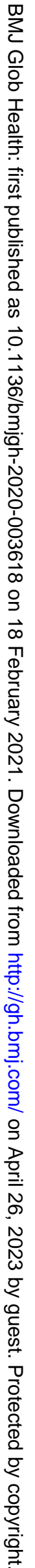




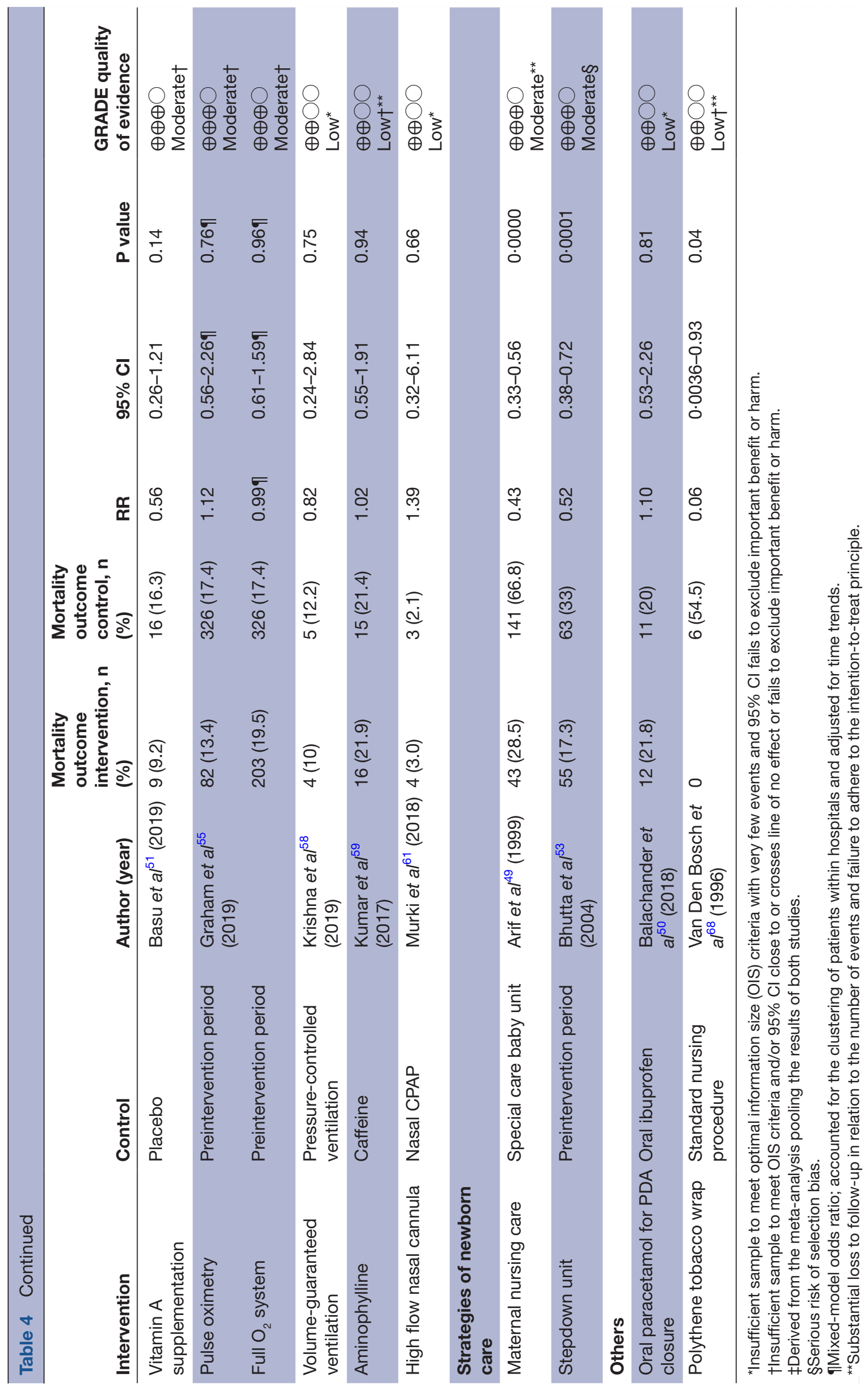




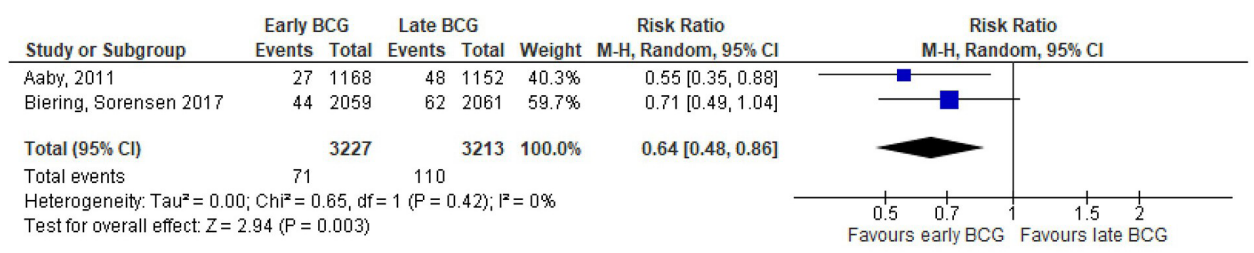

Meta-analysis addressing the effect of early versus late BCG on 28-day neonatal mortality among LBW neonates.

\begin{tabular}{|c|c|c|c|c|c|c|}
\hline Study or Subgroup & log[Odds Ratio] & SE & Weight & $\begin{array}{c}\text { Odds Ratio } \\
\mathrm{IV} \text {, Random, } 95 \% \mathrm{Cl}\end{array}$ & $\begin{array}{r}\text { Odds } \\
\text { IV, Randor }\end{array}$ & $\begin{array}{l}\text { Ratio } \\
\mathrm{m}, 95 \% \mathrm{Cl}\end{array}$ \\
\hline Mazumder, 2019 & -0.349 & 0.1591 & $83.6 \%$ & $0.71[0.52,0.96]$ & $=$ & \\
\hline Sloan, 2008 & -0.1393 & 0.3596 & $16.4 \%$ & $0.87[0.43,1.76]$ & & \\
\hline Total $(95 \% \mathrm{Cl})$ & & & $100.0 \%$ & $0.73[0.55,0.97]$ & & \\
\hline \multicolumn{5}{|c|}{$\begin{array}{l}\text { Heterogeneity: } \text { Tau }^{2}=0.00 ; \mathrm{Chi}^{2}=0.28, \mathrm{df}=1(\mathrm{P}=0.59) ; \mathrm{I}^{2}=0 \% \\
\text { Test for overall effect: } Z=2.16(P=0.03)\end{array}$} & $\begin{array}{cc}0.5 & 0.7 \\
\text { Favours communi }\end{array}$ & $\begin{array}{cc}1.5 & 2 \\
\text { Favours standard care }\end{array}$ \\
\hline
\end{tabular}

Meta-analysis addressing the effect of community KMC versus standard home-based care on 28-day neonatal mortality among LBW neonates.

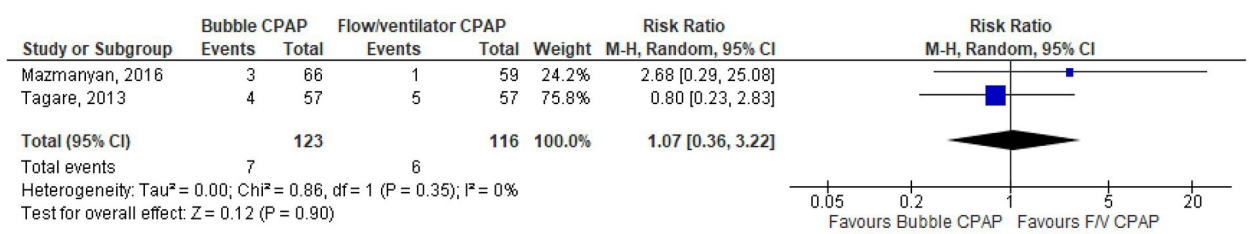

Meta-analysis addressing the effect of Bubble CPAP versus conventional CPAP on mortality during hospital stay among preterm neonates.

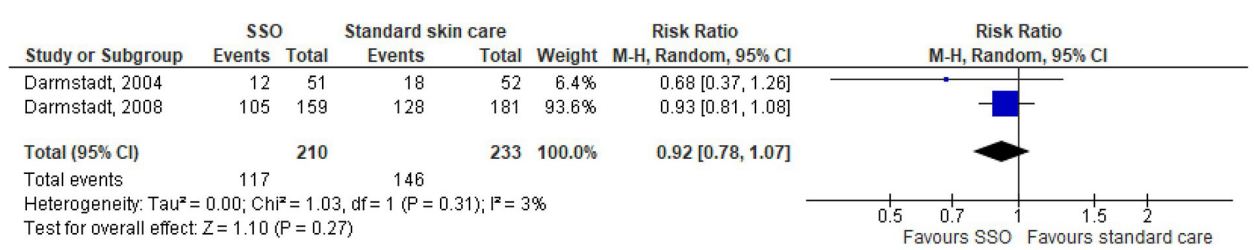

Meta-analysis addressing the effect of topical ointment therapy with Sunflower Seed Oil versus standard skin care on 28-day neonatal mortality among preterm neonates.

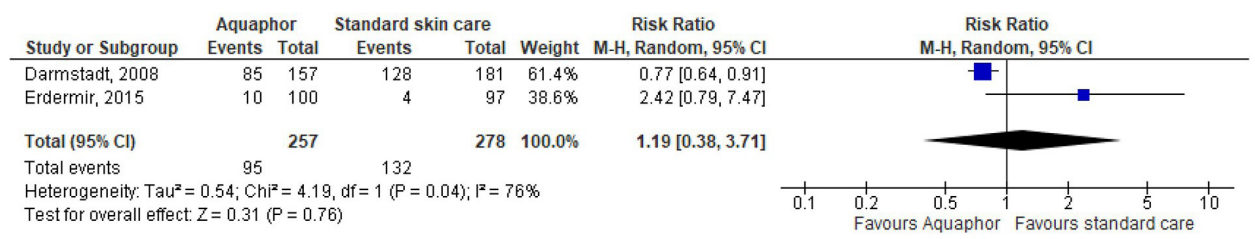

Meta-analysis addressing the effect of topical ointment therapy with Aquaphor versus standard skin care on 28-day and 21-day neonatal mortality among preterm neonates.

Figure 2 Forest plots. BCG, bacille calmette-guérin; CPAP, continuous positive airway pressure; KMC, kangaroo mother care; LBW, low birth weight.

their individual study sites. Significant reductions in 28-day NMR among <5th percentile births were only observed in Guatemala and Pakistan study sites. ${ }^{36} 39$

Skin cleansing with chlorhexidine versus placebo was studied in rural Nepal. Significantly reduced NMR was recorded among LBW neonates (RR 0.72; 95\% CI $0.55-0.95) .{ }^{46}$ Likewise, single cord cleansing with chlorhexidine versus standard care led to significantly reduced NMR among preterm neonates $(0.65 ; 0.50-0.86)$ in rural Bangladesh. ${ }^{27}$

Two studies assessed the effect of early versus late $B C G$ vaccination among LBW neonates in urban districts of Guinea-Bissau consecutively. Both studies showed a significant reduction in NMR $(0.55 ; 0.35-0.88) \quad(0.71$; $0.49-1.04) .^{2431}$

Community $K M C$ versus standard home-based care was studied among LBW neonates. In rural and semiurban areas of India, a significant reduction in 28-day NMR was reported $(0.71 ; 0.52-0.96) .{ }^{40}$ Similarly, in rural Bangladesh 28-day NMR decreased significantly among LBW neonates weighing $\leq 2000 \mathrm{~g}$ (OR $0.37 ; 0.16-0.86)$. The same study did not find a significant difference in 28-day NMR among neonates weighing $\leq 2500 \mathrm{~g}$ (OR 0.87; $0.43-1.74) .{ }^{45}$ A before-after study of home-based newborn 


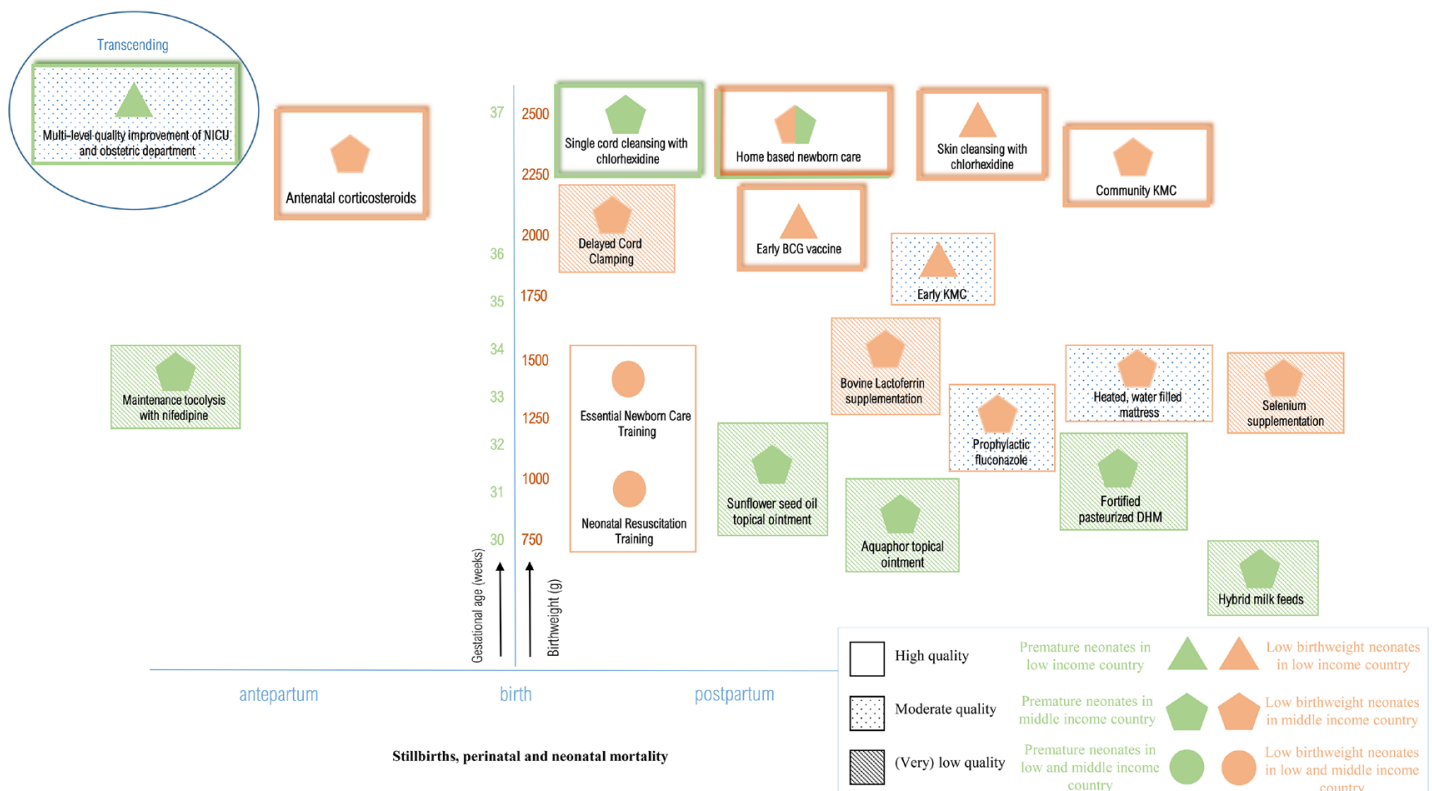

Figure 3 Summary of main findings. BCG; bacille calmette-guérin; DHM, donor human milk; KMC, kangaroo mother care; NICU, neonatal intensive care unit

care in rural India showed a significant reduction in NMR among LBW neonates $(0.42 ; 0.27-0.65)$ and preterm neonates $(0.25 ; 0.14-0.48){ }^{28-30}$

Essential newborn care (ENC) training and neonatal resuscitation programme (NRP) were delivered to birth attendants in six MICs. No significant differences in perinatal (ENC: $1.02 ; 0.91-1.14 / \mathrm{NRP}: 0.95 ; 0.84-1.07$ ) and 7-day NMR (ENC: $1.03 ; 0.83-1.27 / N R P: 0.92 ; 0.77-1.09$ ) were observed. ${ }^{22}$

Meta-analysis

Pooled estimates of two studies assessing the effects of early versus late $B C G$ vaccination among $\mathrm{LBW}$ neonates in urban districts of Guinea-Bissau showed a significant reduction in NMR $(0.64 ; 0.48-0.86) .{ }^{24} 31$

The pooled mortality estimates of community KMC showed a significantly lower 28-day NMR in the intervention group (OR $0.73 ; 0.55-0.97) .^{40} 45$

\section{Moderate quality}

Four studies on neonatal mortality were considered of moderate quality. These studies assessed the effect of a quality improvement intervention introduction in the obstetric department and neonatal intensive care unit (NICU), heated mattress, prophylactic fluconazole, and early KMC on NMR. ${ }^{32} 38444$

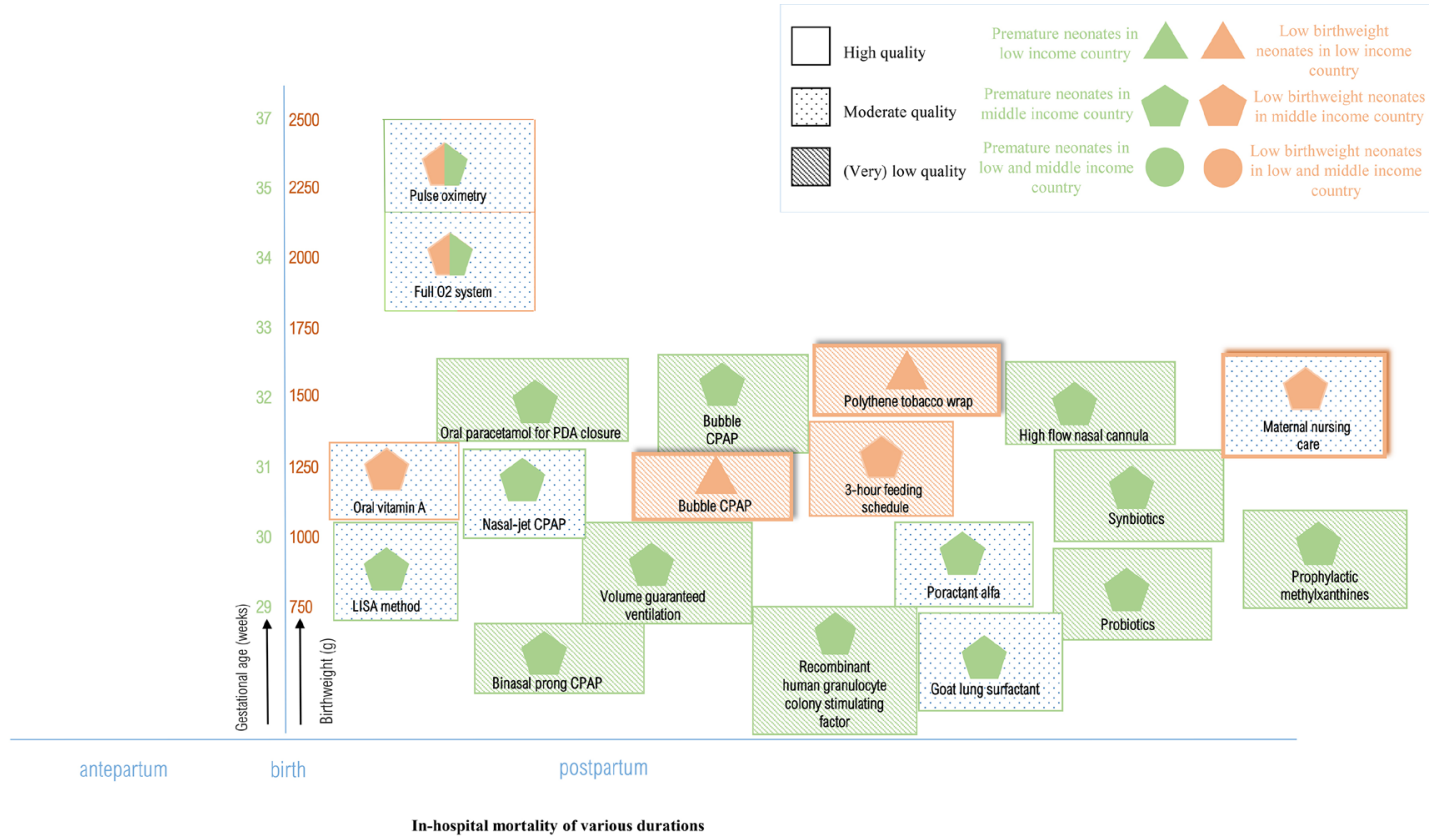

Figure 4 Summary of findings post hoc analysis. CPAP, continuous positive airway pressure; PDA, patent ductus arteriosus. 

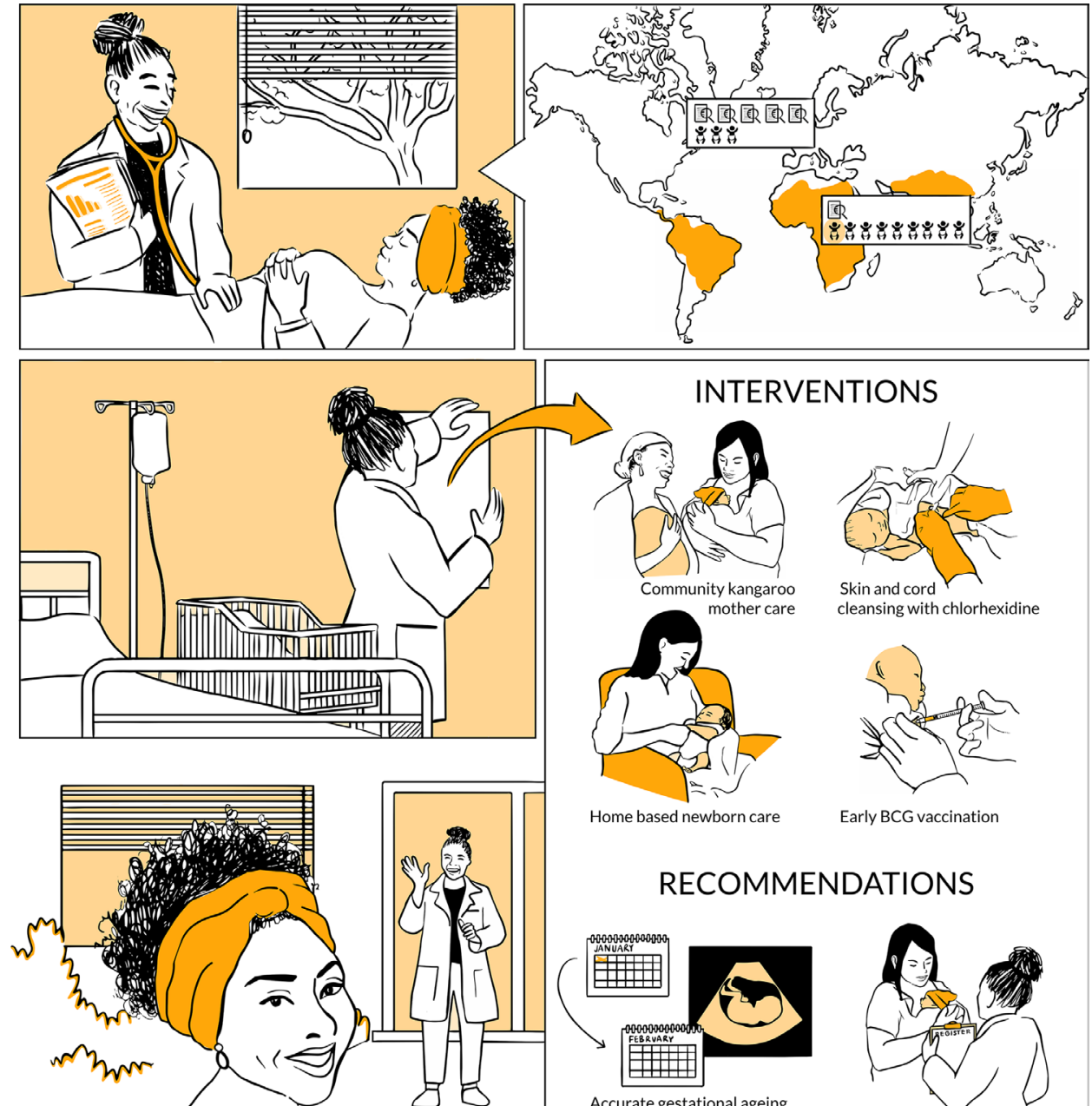

Home based newborn care

Early BCG vaccination

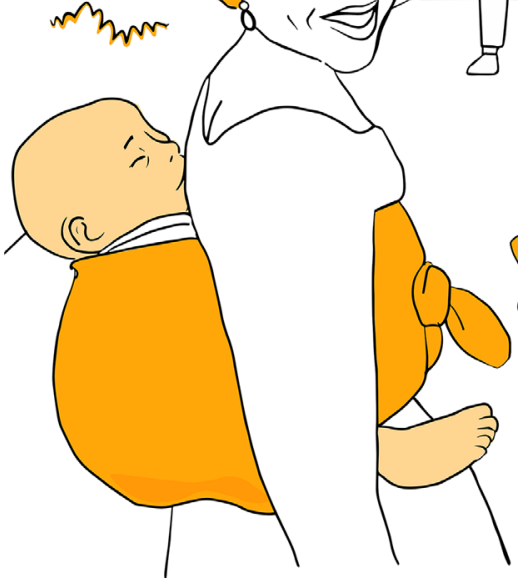

RECOMMENDATIONS

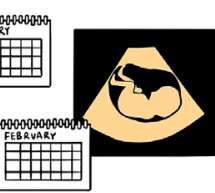

Accurate gestational ageing
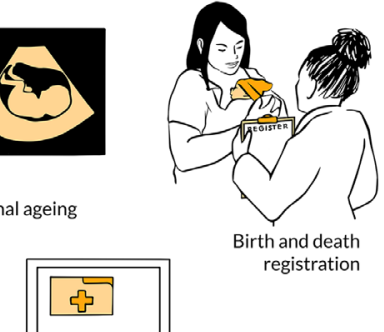

registration

Figure 5 infographic. This infographic tells the story of a health professional in a low-resource setting. She explains to her patient, a woman in her early pregnancy, that there is an increased risk of neonatal mortality in case her newborn is born preterm or growth-restricted. She shows a set of evidence-based interventions and recommendations she is about to implement to reduce this risk, strengthen newborn health care, and ultimately reduce under-five mortality (SDG 3.2).

The multilevel quality improvement intervention implemented protocols for the infrastructure, equipment and daily clinical routine at the NICU and obstetric department of a large public hospital in Mozambique. This resulted in a significant decline of NMR in premature neonates $(0.77 ; 0.66-0.90){ }^{32}$

Heated, water-filled mattresses were evaluated in a study by Sarman et al to prevent hypothermia among LBW neonates at a neonatal care unit in Turkey. Neonatal mortality rate did not change significantly in comparison with air heated incubators (21.4\% vs $34.4 \%$; $0.62 ; 0.26-1.47){ }^{44}$

Prophylactic fluconazole versus placebo in very LBW neonates was studied at a NICU in India. No significant difference in neonatal mortality rate was observed ( $18.4 \%$ vs $32.4 \%$; RR $0.57,95 \%$ CI $0.25-1.28) .{ }^{38}$

Early $K M C$ versus conventional care in LBW neonates was implemented by Worku et al in a tertiary hospital in Ethiopia. The neonatal mortality rate showed a trend 
towards a significant decline $(22.5 \%$ vs $38 \% ; 0.57$; $0.33-1.00){ }^{47}$

\section{Low or very low quality}

Eight studies reported low-quality or very low-quality results. Corresponding studies addressed the effect of maintenance tocolysis, feeding supplements, and delayed cord clamping, all versus standard care or placebo. ${ }^{21} 263337$ The same applies to fortified versus unfortified pasteurised donor human milk, hybrid milk versus mother's milk alone, and sunflower seed oil and Aquaphor versus standard care. 2325343542

\section{Meta-analysis}

The meta-analyses of topical ointment with sunflower seed oil versus standard care $(0.92 ; 0.78-1.07)$ and Aquaphor versus standard care $(1.19 ; 0.38-3.71)$ showed high heterogeneity and no significant differences in NMR. ${ }^{23} 3435$

\section{Post hoc analysis of in-hospital mortality}

First, eight studies of moderate quality are described, assessing nasal-jet versus bubble CPAP, less-invasive surfactant administration (LISA) versus conventional intubation surfactant administration and extubation (INSURE), surfactant agents of porcine, bovine and caprine origin, vitamin A, introducing pulse oximetry, full oxygen system, maternal nursing and a stepdown unit involving maternal nursing. ${ }^{491-57}$ Studies with lowquality evidence are briefly mentioned.

\section{Moderate quality}

Bhatti et al studied nasal-jet CPAP versus bubble CPAP in neonates with gestational age $<34$ weeks at two NICUs in India. No significant effect on in-hospital mortality was observed (25\% vs $18 \% ; 1.41 ; 0.78-2.52){ }^{52}$

Two different surfactant agents of porcine and bovine origin for preterm neonates with IRDS were introduced by Gharehbaghi et al (poractant alfa vs beractant: $26.6 \%$ vs $21.1 \% ; 1.26 ; 0.70-2.25$ ) and Jain et al (goat lung surfactant extract vs beractant: $40.4 \%$ vs $30.4 \%$; $1.33 ; 0.77-2.30$ ) at NICUs in Iran and India. No significant difference in mortality rate was reported. ${ }^{54}{ }^{57}$ LISA, studied versus the INSURE method, did not affect mortality rate among preterm neonates at a neonatal unit in Pakistan $(38 \%$ vs $56 \% ; 0.68 ; 0.44-1.04) .{ }^{56}$

Basu et al administered oral vitamin $A$ versus placebo to VLBW neonates at a NICU in India which did not result in a significant different mortality rate $(9.2 \%$ vs $16.3 \%$; $0.56 ; 0.26-1.21) .^{51}$

Two oxygen systems were studied in a before-after study by Graham et al in 12 hospitals in Nigeria. Introduction of pulse oximetry to improve oxygen practices did not show a significant difference in mortality among LBW and preterm neonates $(13.4 \%$ vs $17.4 \%$; OR 1.12 ; $0.56-$ 2.26). Likewise, introduction of a multifaceted, full oxygen system, did not alter the mortality significantly $(19.5 \%$ vs $17.4 \%$; $0.99 ; 0.61-1.59) .{ }^{55}$

LBW neonates weighing 1000-2000 g on admission were randomised to maternal nursing care or conventional nursing care at a neonatal ward in Pakistan. A significantly declined mortality rate until hospital discharge was observed in the maternal nursing group (28.5\% vs $66.8 \% ; 0.43 ; 0.33-0.56){ }^{49}$

In a before-after study, Bhutta et al introduced a stepdown unit at a neonatal ward in Pakistan. The unit had a nursing ratio of $1: 5$ compared with 1:3 at the conventional ward. Co-bedding was established, number of visitors was minimalised and mothers were involved in regular monitoring of vital signs and temperature. A significant lower mortality rate was observed after the unit was created $(17.3 \%$ vs $33 \%$; $0.52 ; 0.38-0.72) .^{53}$

\section{Low or very low quality}

Thirteen studies reported low or very low quality results of in-hospital mortality following different interventions. Among these, six interventions were compared with standard care or placebo: a 3-hour feeding schedule, probiotics and synbiotics, granulocyte stimulating agent, volume guaranteed ventilation and polythene tobacco wrap. $^{48} 5862646768$ Other interventions with (very) low quality results studied high-flow nasal cannula versus nasal CPAP, binasal prong versus nasal mask for applying CPAP, aminophylline versus caffeine for extubation failure, oral paracetamol versus ibuprofen for patent ductus arteriosus (PDA) closure, introduction of bubble CPAP, and bubble versus conventional CPAP. $.^{50} 59-61636566$

\section{Risk of bias}

Tables 7-9 (online supplemental appendix) show the risk of bias assessment of individual studies. Overall, the risk of bias in randomised studies was considered 'some concerns' in 30 studies and 'high risk' in 13. Only one study scored low risk for all domains. ${ }^{40}$ Most studies failed to report on the use of a prespecified analysis plan in the methods section. The studies generally performed well in terms of outcome measurement (96\% low risk) and missing outcome data ( $88 \%$ low risk). Several studies displayed a moderate or high risk of bias in the randomisation process $(44 \%)$ and deviations from intended interventions $(74 \%)$. The bias risk in before-after studies varied from low to critical risk, particularly due to the risk of confounders and selection bias. ${ }^{22} 28-30325363$

\section{Quality of evidence}

The GRADE evidence profiles are provided in tables 5 and 6 of the online supplemental appendix. The summarised results are listed in tables 3 and 4 of the manuscript.

\section{SWOT analysis}

Table 10 (online supplemental appendix) provides SWOT analysis. ${ }^{69-78}$

The strengths of the interventions addressed in this study generally pertain to their accessibility, acceptability, applicability, affordability and scale-up ability without disrupting mother-infant bonding.

The weaknesses of the interventions are the requirements of the minimal clinical infrastructure, for example, gestational age determination, adequate neonatal care, 
skills retainment or adequate follow-up system to evaluate long-term effects.

Opportunities are conducting implementation studies to determine the most effective strategy, subsequent implementation and scale-up of interventions including smooth embedding in the existing (inter) national guidelines. Many interventions such as chlorhexidine are widely available, listed as essential drugs or already culturally accepted.

Barriers to implementation generally pertain to limited availability of equipment, resources or skilled health personnel, cultural or traditional unacceptability, dysfunctional safety measures and limited access to tertiary health centres/NICUs.

\section{DISCUSSION}

This systematic review summarises the evidence on 38 interventions evaluated in 49 studies among 46993 participants across 21 LMICs. The 12 studies with high quality of evidence showed lower neonatal mortality rates among preterm and LBW neonates with the use of skin and cord cleansing with chlorhexidine, early BCG vaccination, community KMC and home-based newborn care. ${ }^{2427-31404546}$ The effects on NMR of antenatal corticosteroids varied. No effects on mortality rates were observed among VLBW neonates following training of birth attendants in neonatal resuscitation and essential newborn care. ${ }^{20} 223639$ Remaining studies showed significant shortcomings in quality and diverse impacts on mortality rates.

In 2015, the WHO published recommendations on interventions to improve preterm birth outcomes. ${ }^{4}$ This WHO report was based on priority questions formulated by experts in the field of maternal and neonatal care. These questions resulted in eleven PICO's (Patient, Intervention, Control, Outcome), addressing nine different antenatal, perinatal and postnatal interventions. The available evidence concerning the selected interventions was reviewed and synthesised into a guideline, focusing on maternal and neonatal mortality and morbidity outcomes related to preterm birth.

In our study, we reviewed all existing evidence on interventions to reduce, specifically, neonatal mortality among preterm and/or LBW neonates. We did not focus on a preliminary selection of interventions, and included preterm and growth-restricted neonates. We were therefore able to identify a larger number of interventions, among which some were not previously considered in the WHO guideline.

The 2015 WHO guideline recommends antenatal corticosteroid therapy for women at risk of preterm birth at $24^{0 / 7}-34^{0 / 7}$ weeks of gestation. In the ACT trial, corticosteroids increased neonatal mortality among the intervention group. ${ }^{20}$ Absence of effect in the intervention group could be due to the outcome definition with birth weight $<5$ th percentile as a proxy for preterm birth. As such, the intervention group may have partially consisted of growth-restricted and near-term neonates for whom corticosteroids are not recommended. The Guatemalan and (to a lesser extent) Pakistan sites showed a significant reduction in NMR among $<5$ th percentile neonates, which might be attributed to the higher level of care and greater ACS use. ${ }^{36}$ These controversial findings emphasise the need to implement the use of antenatal corticosteroids solely in areas where gestational age dating and adequate maternal and newborn care can be guaranteed. Effectuation should be dependent on these conditions, and results carefully monitored. This is supported by the recently published WHO Antenatal Dexamethasone for Early Preterm Birth in Low-Resource Countries (ACTION) trial that showed a positive effect of antenatal dexamethasone treatment on stillbirth and neonatal mortality in early preterm neonates in secondary and tertiary hospitals in India, Pakistan, Kenya, Nigeria and Bangladesh (NMR: $19.6 \%$ vs 23.5\%; RR $0.84(0.72-0.97)$ । stillbirth or NMR: $25.7 \%$ vs $29.2 \%$; RR $0.88(0.78-0.99) .^{79}$

$\mathrm{KMC}$ is strongly recommended for newborns of birth weight $\leq 2000 \mathrm{~g}$ in the WHO guideline and the 2016 Cochrane review. ${ }^{40}$ Likewise, the ENAP states that by $2025 \geq 75 \%$ of stable preterm newborns or babies $<2000$ g should receive KMC. ${ }^{3}$ Our meta-analysis on community KMC shows a reduced neonatal mortality for all LBW neonates (ie, $<2500 \mathrm{~g}$ ) at the community level (high certainty of evidence).

In view of the large number of neonatal deaths caused by infant respiratory distress syndrome, CPAP therapy is strongly recommended by the WHO despite the lowquality evidence in LMICs. ${ }^{4}$ Thukral et al expressed the urgent need for high-quality studies on CPAP therapy among LMICs. ${ }^{81}$ The results of the studies included in our review addressing different CPAP devices are in line with these studies. Our SWOT analysis identifies bubble CPAP as the most cost-effective, easy-to-use and safe device in settings with trained staff but limited resources.

We found high-quality evidence based on two community trials for reducing the NMR among premature and LBW neonates after skin and cord chlorhexidine application. This finding aligns with the Cochrane review of term or late preterm neonates $>2500 \mathrm{~g}$, suggesting reduced neonatal mortality in the community setting. ${ }^{82}$ Likewise, the WHO recommends daily chlorhexidine application for home births in settings with high neonatal mortality. ${ }^{83}$ Based on our findings, the WHO could consider to extend this recommendation to LBW and preterm neonates.

The strengths of this review are the comprehensiveness reflected in the large number of interventions and included participants, the SWOT analysis and metaanalysis where appropriate. Several limitations must be considered in the interpretation of findings. First, the inherent limitation linked to the overall moderateto-low quality of included studies, not always powered for neonatal mortality endpoints or within the same timeframe. This may be explained by the resource constrictions of many healthcare settings in LMICs but also underlines the urgency of strengthening the research 
infrastructure to answer urgent clinical questions in real-life contexts using optimal scientific approaches. Second, publication bias may be present because studies performed in low-resource settings may go unpublished and unindexed by international journals or databases. This could partly explain the scarcity of studies from lowincome countries. The scarcity of studies is also represented in the meta-analysis, which is limited in quality due to the few number of studies included. Third, our SWOT analysis was primarily based on study author-reported characteristics of interventions, which may lead to underreporting of weaknesses and barriers to implementation.

Relatively few studies that address antenatal interventions to prevent preterm birth could be included. These studies' outcomes usually focus on incidence of prematurity rather than perinatal mortality, while this can be included relatively easily in future study reports. Similarly, presentation of mortality disaggregated by prematurity and/or LBW incidence or availability of study datasets ${ }^{84}$ would allow more interventions to be evaluated in future (individual participant data) systematic reviews.

\section{CONCLUSION}

Given the global commitment to end preventable deaths of newborns and children less than 5 years old in SDG 3.2 , ongoing preventable mortality among preterm and LBW neonates needs urgent attention. This manuscript provides sufficient high-quality evidence to consider implementation of additional low-cost, high-benefit interventions in current guidelines; cord and skin cleansing with chlorhexidine, community KMC for LBW neonates, home-based newborn care and early BCG vaccination for LBW neonates. These interventions are accessible, acceptable, applicable and affordable.

These practices are currently not recommended in most countries. Given the circumstances and possibilities in research in LMICs, evidence is sufficient although not high in quantity (in relation to the quantity and quality of data from high-income countries related to this topic) to discourage current underutilisation of health practices and opportunities and consider to update present guidelines.

We highlight the importance of accurately imbedding or optimal usage of maternal and newborn healthcare practices such as gestational age dating and birth and death registration in order to benefit from and investigate any intervention. Antenatal corticosteroid treatment should be implemented if adequate gestational age dating is available and adequate maternal and neonatal care is provided.

There is an urgent need for high-quality evidence to guide clinical and public health practice in LMICs. These should focus on strategies to prevent and manage common complications in preterm and LBW neonates. ${ }^{1}$ Beyond classic RCTs, relatively novel scientific approaches such as stepped-wedge $\mathrm{RCTs},{ }^{85}$ implementation-evaluation studies and learning health system research based on routinely collected (electronic) patient data should be considered.

An infographic that summarizes the main outcomes and recommendations of this study is provided in figure 5 .

\section{Author affiliations}

${ }^{1}$ Department of Neonatology, Sint Antonius Hospital, Nieuwegein, The Netherlands ${ }^{2}$ Department of Neonatology, Wilhelmina Children's Hospital University Medical Center Utrecht, Utrecht, The Netherlands

${ }^{3}$ Julius Global Health, Julius Center for Health Sciences and Primary Care, University Medical Center Utrecht, Utrecht, The Netherlands

${ }^{4}$ Department of Child Health, Korle-Bu Teaching Hospital, Accra, Ghana

${ }^{5}$ Department of Obstetrics and Gynaecology, Korle-Bu Teaching Hospital, Accra, Ghana

${ }^{6}$ College of Health Sciences, Samara University, Semera, Afar, Ethiopia

${ }^{7}$ Swiss Tropical and Public Health Institute, Basel, Switzerland

${ }^{8}$ Department of Obstetrics and Gynaecology, University Medical Center Utrecht, Utrecht, The Netherlands

Acknowledgements We would like to thank information specialist, Dr Paulien Wiersma, who supported us in developing our search strategy. We would like to thank Professor Dr Rob Scholten and Dr Peter Zuithoff for their statistical advice on the Results and Meta-analysis sections. We would like to thank medical illustrator, Anna Sieben, for the design of a visual summary that supports our study.

Contributors *Joint first authors: MK and MS contributed equally to this paper and would like to be stated as joint first authors in the published version of the manuscript in BMJ Global Health. MK proposed the research question and MK, MS and JLB designed the study. MS and MK performed the literature search, study selection and data extraction with support of JLB. MS performed statistical analysis and designed tables and figures. FG aided in the statistical analysis. MS wrote the first draft of the manuscript, with continuous input from MK. All authors critically and equally reviewed and edited the manuscript.

Funding The authors have not declared a specific grant for this research from any funding agency in the public, commercial or not-for-profit sectors.

\section{Competing interests None declared.}

Patient consent for publication Not required.

Provenance and peer review Not commissioned; externally peer reviewed.

Data availability statement Data are available upon request. All data relevant to the study are included in the article or uploaded as supplementary information. All data relevant to the study are included in the article or uploaded as supplementary information. Additional data extracted from the included studies, but not directly relevant to the study, are available upon request from the corresponding author (ORCID-ID 0000-0001-9323-4436, e-mail: merel.stevens@hotmail.com).

Supplemental material This content has been supplied by the author(s). It has not been vetted by BMJ Publishing Group Limited (BMJ) and may not have been peer-reviewed. Any opinions or recommendations discussed are solely those of the author(s) and are not endorsed by BMJ. BMJ disclaims all liability and responsibility arising from any reliance placed on the content. Where the content includes any translated material, BMJ does not warrant the accuracy and reliability of the translations (including but not limited to local regulations, clinical guidelines, terminology, drug names and drug dosages), and is not responsible for any error and/or omissions arising from translation and adaptation or otherwise.

Open access This is an open access article distributed in accordance with the Creative Commons Attribution Non Commercial (CC BY-NC 4.0) license, which permits others to distribute, remix, adapt, build upon this work non-commercially, and license their derivative works on different terms, provided the original work is properly cited, appropriate credit is given, any changes made indicated, and the use is non-commercial. See: http://creativecommons.org/licenses/by-nc/4.0/.

\section{ORCID iD}

Merel M Stevens http://orcid.org/0000-0001-9323-4436

\section{REFERENCES}

1 Chawanpaiboon S, Vogel JP, Moller A-B, et al. Global, regional, and national estimates of levels of preterm birth in 2014: a systematic review and modelling analysis. Lancet Glob Health 2019;7:e37-46. 
2 United Nations Inter-agency Group for Child Mortality Estimation (UN IGME). Levels \& Trends in Child Mortality: Report 2019, Estimates developed by the United Nations Inter-agency Group for Child Mortality Estimation. New York: United Nations Children's Fund, 2019.

3 UNICEF. Every newborn: an action plan to end preventable deaths: Executive summary. Geneva: World Health Organization, 2014.

4 WHO. Recommendations on interventions to improve preterm birth outcomes. Geneva: World Health Organization, 2015.

5 Blencowe H, Cousens S, Oestergaard MZ, et al. National, regional, and worldwide estimates of preterm birth rates in the year 2010 with time trends since 1990 for selected countries: a systematic analysis and implications. Lancet 2012;379:2162-72.

6 Katz J, Lee AC, Kozuki N. CHERG Small-for-Gestational-AgePreterm birth Working Group. mortality risk in preterm and small-forgestational-age infants in low-income and middle-income countries: a pooled country analysis. Lancet 2013;382:417-25.

7 Gidi NW, Goldenberg RL, Nigussie AK, et al. Comparison of neonatal outcomes of small for gestational age and appropriate for gestational age preterm infants born at 28-36 weeks of gestation: a multicentre study in Ethiopia. BMJ Paediatr Open 2020;4:e000740.

8 Higgins JPT, Thomas J, Chandler J. Cochrane Handbook for Systematic Reviews of Interventions. Chichester (UK: John Wiley \& Sons, 2019.

9 Moher D, Liberati A, Tetzlaff J, et al. Preferred reporting items for systematic reviews and meta-analyses: the PRISMA statement. PLoS Med 2009;6:e1000097.

10 World Health Organization. Neonatal and perinatal mortality: country regional and global estimates, 2006. Available: https://apps.who.int/ iris/handle/10665 [Accessed 28 Nov 2019].

11 The world bank. world bank country and lending groups. Available: https://datahelpdesk.worldbank.org/knowledgebase/articles/ 906519-world-bankcountry-and-lending-groups [Accessed $28 \mathrm{Nov}$ 2019].

12 Bmi group. search blocks. Available: https://www.bmi-online.nl/ searchblocks/search-blocks-bmi/ [Accessed 6 Jul 2019].

13 Ouzzani M, Hammady H, Fedorowicz Z, et al. Rayyan-a web and mobile APP for systematic reviews. Syst Rev 2016;5:210.

14 Sterne JAC, Savović J, Page MJ, et al. Rob 2: a revised tool for assessing risk of bias in randomised trials. BMJ 2019;366:14898.

15 Sterne JA, Hernán MA, Reeves BC, Savović J, et al. ROBINS-I: a tool for assessing risk of bias in non-randomised studies of interventions. BMJ 2016;355:14919.

16 Anthon CT, Granholm A, Perner A, et al. No firm evidence that lack of blinding affects estimates of mortality in randomized clinical trials of intensive care interventions: a systematic review and metaanalysis. J Clin Epidemiol 2018;100:71-81.

17 et al.Schünemann H, Brożek J, Guyatt G. GRADE handbook for grading quality of evidence and strength of recommendations. Updated October 2013. The GRADE Working Group, 2013. Available from. Available: guidelinedevelopment.org/handbook.

18 Review Manager (RevMan) [Computer program]. Version 5.3. Copenhagen: The Nordic Cochrane Centre, The Cochrane Collaboration, 2014

19 Helms M, Nixon J. Exploring SWOT analysis - where are we now? : A review of academic research from the last decade. J Econ Manag Strat 2010;3:215-51.

20 Althabe F, Belizán JM, McClure EM, et al. A population-based, multifaceted strategy to implement antenatal corticosteroid treatment versus standard care for the reduction of neonatal mortality due to preterm birth in low-income and middleincome countries: the act cluster-randomised trial. Lancet 2015;385:629-39.

21 Aggarwal A, Bagga R, Girish B, et al. Effect of maintenance tocolysis with nifedipine in established preterm labour on pregnancy prolongation and neonatal outcome. J Obstet Gynaecol 2018;38:177-84.

22 Carlo WA, Goudar SS, Jehan I, et al. High mortality rates for very low birth weight infants in developing countries despite training. Pediatrics 2010;126:e1072-80.

23 Erdemir A, Kahramaner Z, Yuksel Y, et al. The effect of topical ointment on neonatal sepsis in preterm infants. J Matern Fetal Neonatal Med 2015;28:33-6.

24 Aaby $\mathrm{P}$, Roth $\mathrm{A}$, Ravn $\mathrm{H}$, et al. Randomized trial of BCG vaccination at birth to low-birth-weight children: beneficial nonspecific effects in the neonatal period? J Infect Dis 2011;204:245-52.

25 Adhisivam B, Kohat D, Tanigasalam V, et al. Does fortification of pasteurized donor human milk increase the incidence of necrotizing enterocolitis among preterm neonates? A randomized controlled trial. J Matern Fetal Neonatal Med 2019;32:1-6.
26 Aggarwal R, Gathwala G, Yadav S, et al. Selenium supplementation for prevention of late-onset sepsis in very low birth weight preterm neonates. J Trop Pediatr 2016;62:185-93.

27 Arifeen SE, Mullany LC, Shah R, et al. The effect of cord cleansing with chlorhexidine on neonatal mortality in rural Bangladesh: a community-based, cluster-randomised trial. Lancet 2012;379:1022-8.

28 Bang AT, Baitule SB, Reddy HM, et al. Low birth weight and preterm neonates: can they be managed at home by mother and a trained village health worker? J Perinatol 2005;25 Suppl 1:S72-81.

29 Bang AT, Bang RA, Baitule SB, et al. Effect of home-based neonatal care and management of sepsis on neonatal mortality: field trial in rural India. Lancet 1999;354:1955-61.

30 Bang AT, Reddy HM, Deshmukh MD, et al. Neonatal and infant mortality in the ten years (1993 to 2003) of the Gadchiroli field trial: effect of home-based neonatal care. J Perinatol 2005;25 Suppl 1:S92-107.

31 Biering-Sørensen S, Aaby P, Lund N, et al. Early BCG-Denmark and Neonatal Mortality Among Infants Weighing <2500 g: A Randomized Controlled Trial. Clin Infect Dis 2017;65:1183-90.

32 Cavicchiolo ME, Lanzoni P, Wingi MO, et al. Reduced neonatal mortality in a regional hospital in Mozambique linked to a quality improvement intervention. BMC Pregnancy Childbirth 2016;16:366.

33 Chopra A, Thakur A, Garg P, et al. Early versus delayed cord clamping in small for gestational age infants and iron stores at 3 months of age - a randomized controlled trial. BMC Pediatr 2018; $18: 234$.

34 Darmstadt GL, Badrawi N, Law PA, et al. Topically applied sunflower seed oil prevents invasive bacterial infections in preterm infants in Egypt: a randomized, controlled clinical trial. Pediatr Infect Dis J 2004;23:719-25.

35 Darmstadt GL, Saha SK, Ahmed ASMNU, et al. Effect of skin barrier therapy on neonatal mortality rates in preterm infants in Bangladesh: a randomized, controlled, clinical trial. Pediatrics 2008;121:522-9.

36 Garces A, McClure EM, Figueroa L, et al. A multi-faceted intervention including antenatal corticosteroids to reduce neonatal mortality associated with preterm birth: a case study from the Guatemalan Western highlands. Reprod Health 2016;13:63.

37 Kaur G, Gathwala G. Efficacy of bovine lactoferrin supplementation in preventing late-onset sepsis in low birth weight neonates: a randomized placebo-controlled clinical trial. $J$ Trop Pediatr 2015;61:370-6.

38 Kirpal H, Gathwala G, Chaudhary U, et al. Prophylactic fluconazole in very low birth weight infants admitted to neonatal intensive care unit: randomized controlled trial. J Matern Fetal Neonatal Med 2016;29:624-8.

39 Klein K, McClure EM, Colaci D, et al. The antenatal corticosteroids trial (act): a secondary analysis to explore site differences in a multicountry trial. Reprod Health 2016;13:64.

40 Mazumder S, Taneja S, Dube B, et al. Effect of community-initiated kangaroo mother care on survival of infants with low birthweight: a randomised controlled trial. Lancet 2019;394:1724-36.

41 Nagai S, Andrianarimanana D, Rabesandratana N, et al. Earlier versus later continuous kangaroo mother care (KMC) for stable low-birth-weight infants: a randomized controlled trial. Acta Paediatr 2010;99:827-35

42 Nandakumar A, Pournami F, Prabhakar J. Exclusive breast milk vs. hybrid milk feeding for preterm Babies-A randomized controlled trial comparing time to full feeds. J Trop Pediatr 2020;66:1-3.

43 Rasool A, Faroog U, Nazir Q-U-A, et al. Efficacy of two regimens of dexamethasone for management of preterm labour: pilot study. $J$ Ayub Med Coll Abbottabad 2017;29:393-7.

44 Sarman I, Can G, Tunell R. Rewarming preterm infants on a heated, water filled mattress. Arch Dis Child 1989;64:687-92.

45 Sloan NL, Ahmed S, Mitra SN, et al. Community-Based kangaroo mother care to prevent neonatal and infant mortality: a randomized, controlled cluster trial. Pediatrics 2008;121:e1047-59.

46 Tielsch JM, Darmstadt GL, Mullany LC, et al. Impact of newborn skin-cleansing with chlorhexidine on neonatal mortality in southern Nepal: a community-based, cluster-randomized trial. Pediatrics 2007;119:e330-40.

47 Worku B, Kassie A. Kangaroo mother care: a randomized controlled trial on effectiveness of early kangaroo mother care for the low birthweight infants in Addis Ababa, Ethiopia. J Trop Pediatr 2005;51:93-7.

48 Aktas D, Demirel B, Gürsoy T, et al. A randomized case-controlled study of recombinant human granulocyte colony stimulating factor for the treatment of sepsis in preterm neutropenic infants. Pediatr Neonatol 2015;56:171-5. 
49 Arif MA, Arif K. Low birthweight babies in the third world: maternal nursing versus professional nursing care. J Trop Pediatr 1999;45:278-80.

50 Balachander B, Mondal N, Bhat V, et al. Comparison of efficacy of oral paracetamol versus ibuprofen for PDA closure in preterms - a prospective randomized clinical trial. J Matern Fetal Neonatal Med 2020;33:1587-1592.

51 Basu S, Khanna P, Srivastava R. Oral vitamin A supplementation in very low birth weight neonates: a randomized controlled trial. Eur J Pediatr 2019;178(8:1255-65.

52 Bhatti A, Khan J, Murki S. Nasal Jet-CPAP (variable flow) versus Bubble-CPAP in preterm infants with respiratory distress: an open label, randomized controlled trial. J Perinatol 2015;35:935-40.

53 Bhutta ZA, Khan I, Salat S. Reducing length of stay in hospital for very low birthweight infants by involving mothers in a stepdown unit: an experience from Karachi (Pakistan). BMJ 2004;329:1151-5.

54 Gharehbaghi MM, Sakha SHP, Ghojazadeh M, et al. Complications among premature neonates treated with beractant and poractant alfa. Indian J Pediatr 2010;77:751-4.

55 Graham H, Bakare A, Ayede A. Oxygen systems to improve clinical care and outcomes for children and neonates: a stepped-wedge cluster-randomised trial in Nigeria. PLoS Med2019;16:e1002951.

56 Halim A, Shirazi H, Riaz S. Less invasive surfactant administration in preterm infants with respiratory distress syndrome. J Coll Physicians Surg Pak 2019;29:226-330.

57 Jain K, Nangia S, Ballambattu VB, et al. Goat lung surfactant for treatment of respiratory distress syndrome among preterm neonates: a multi-site randomized non-inferiority trial. J Perinatol 2019;39:3-12.

58 Krishna G, Skariah T, Edward L. Volume-guaranteed ventilation versus pressure-controlled ventilation in preterm infants with respiratory distress syndrome: a randomized controlled trial. Iranian Journal of Neonatology 2019;10:42-6.

59 Kumar MS, Najih M, Bhat YR. Prophylactic methylxanthines for preventing extubation failure in the preterm neonates with the gestational age of $\leq 30$ weeks: a randomized controlled trial. Iranian Journal of Neonatology 2017;8.

60 Mazmanyan P, Mellor K, Doré CJ, et al. A randomised controlled trial of flow driver and bubble continuous positive airway pressure in preterm infants in a resource-limited setting. Arch Dis Child Fetal Neonatal Ed 2016;101:16-20.

61 Murki S, Singh J, Khant C, et al. High-Flow nasal cannula versus nasal continuous positive airway pressure for primary respiratory support in preterm infants with respiratory distress: a randomized controlled trial. Neonatology 2018;113:235-41.

62 Nandhini LP, Biswal N, Adhisivam B, et al. Synbiotics for decreasing incidence of necrotizing enterocolitis among preterm neonates - a randomized controlled trial. J Matern Fetal Neonatal Med 2016;29:821-5.

63 Okello F, Egiru E, Ikiror J, et al. Reducing preterm mortality in eastern Uganda: the impact of introducing low-cost bubble CPAP on neonates <1500 g. BMC Pediatr 2019;19:311.

64 Sari FN, Dizdar EA, Oguz S, et al. Oral probiotics: Lactobacillus sporogenes for prevention of necrotizing enterocolitis in very lowbirth weight infants: a randomized, controlled trial. Eur J Clin Nutr 2011;65:434-9.

65 Say B, Kanmaz Kutman HG, Oguz SS, et al. Binasal prong versus nasal mask for applying CPAP to preterm infants: a randomized controlled trial. Neonatology 2016;109:258-64.
66 Tagare A, Kadam S, Vaidya U, et al. Bubble CPAP versus ventilator CPAP in preterm neonates with early onset respiratory distress--a randomized controlled trial. J Trop Pediatr 2013;59:113-9.

67 Tali SH, Kabra NS, Ahmed J. Effect of feeding schedule on time to reach full feeds in ELBW and VLBW neonates: a randomized trial. Perinatology 2016;17:95-102.

68 Van Den Bosch CA, Nhlane C, Kazembe P. Trial of polythene tobacco-wrap in prevention of hypothermia in neonates less than 1500 Grams. Trop Doct 1996;26:26-8.

69 Sharma IK, Byrne A. Early initiation of breastfeeding: a systematic literature review of factors and barriers in South Asia. Int Breastfeed J 2016;11:17.

70 World Health Organization Model List of Essential Medicines,. 21St list. Geneva: World Health Organization, 2019.

71 Biering-Sorensen S, Andersen A, Ravn H. Early BCG vaccine to lowbirth-weight infants and the effects on growth in the first year of life: a randomised controlled trial. BMC Pediatr 2015;15:137-76.

72 Lawn JE, Davidge R, Paul VK, et al. Born too soon: care for the preterm baby. Reprod Health 2013;10:S5-S.

73 Mueni E, Opiyo N, English M. Caffeine for the management of apnea in preterm infants. Int Health 2009;1:190-5.

74 Kc A, Wrammert J, Nelin V, et al. Evaluation of helping babies breathe quality improvement cycle (HBB-QIC) on retention of neonatal resuscitation skills six months after training in Nepal. BMC Pediatr 2017;17:103.

75 Versantvoort JMD, Kleinhout MY, Ockhuijsen HDL. Helping babies breathe and its effects on intrapartum-related stillbirths and neonatal mortality in low-resource settings: a systematic review. Arch Dis Child 2020;105:127-33.

76 Karan S, Rao SS. Benefits of early maternal participation in care of low birth weight infants leading to early discharge. J Trop Pediatr 1983;29:115-8.

77 Mollura DJ, Lungren MP. Radiology in global health. New York: Springer, 2014

78 Hundscheid T, Onland W, van Overmeire B, et al. Early treatment versus expectative management of patent ductus arteriosus in preterm infants: a multicentre, randomised, non-inferiority trial in Europe (BeNeDuctus trial). BMC Pediatr 2018;18:262.

79 Oladapo OT, Vogel JP, et al. Antenatal dexamethasone for early preterm birth in low-resource countries. $N$ Engl $\mathrm{J} \mathrm{Med}$ 2020;383:2514-25.

80 Conde-Agudelo A, Díaz-Rossello JL. Kangaroo mother care to reduce morbidity and mortality in low birthweight infants. Cochrane Database Syst Rev 2016;8:CD00277168.

81 Thukral A, Sankar MJ, Chandrasekaran A. Efficacy and safety of CPAP in low- and middle-income countries. J Perinatol 2016;36:S21-8.

82 Sinha A, Sazawal S, Pradhan A. Chlorhexidine skin or cord care for prevention of mortality and infections in neonates. Cochrane Database Syst Rev 2015;3:CD007835.

83 WHO. Recommendations on newborn health: guidelines Approved by the who guidelines review Committee. Geneva: World Health Organization, 2017.

84 Wilkinson MD, Dumontier M, Aalbersberg IJ. The fair guiding principles for scientific data management and stewardship. Sci Data 2016:3:160018

85 Joag K, Ambrosio G, Kestler E, et al. Ethical issues in the design and conduct of stepped-wedge cluster randomized trials in low-resource settings. Trials 2019;20:703. 